\title{
Effect of Mesoporous Catalysts on the Mainstream Tobacco Smoke of 3R4F and 1R5F Reference Cigarettes
}

\author{
Antonio Marcilla Gomis, Amparo Gómez Siurana, Deseada Berenguer Muñoz, \\ Isabel Martínez Castellanos, Maribel Beltrán
}

Dpto. Ingeniería Química, Universidad de Alicante, Apdo. 99, 03080 Alicante, Spain

Email address:

antonio.marcilla@ua.es (A. M. Gomis), amparo.gomez@ua.es (A. G. Siurana)

\section{To cite this article:}

Antonio Marcilla Gomis, Amparo Gómez Siurana, Deseada Berenguer Muñoz, Isabel Martínez Castellanos, Maribel Beltrán. Effect of Mesoporous Catalysts on the Mainstream Tobacco Smoke of 3R4F and 1R5F Reference Cigarettes. American Journal of Chemical Engineering. Vol. 3, No. 1, 2015, pp. 1-18. doi: 10.11648/j.ajche.20150301.11

\begin{abstract}
The effect of three synthesised mesoporous catalysts (a SBA-15 and two MCM-41) on the smoke of two reference tobaccos (1R5F and 3R4F) has been studied. Mixtures of the catalysts and each tobacco were smoked under the ISO 3388 standard conditions. The gaseous compounds and the particulate matter condensed in the filter tip (TPM-F) and in a trap located downstream (TPM-T) from the mainstream smoke were analysed separately. The results obtained show that these catalysts directly mixed with tobacco are capable of reducing the yield of most of the compounds studied in the mainstream tobacco smoke. SBA-15 is a better additive for reducing the amount of the compounds analysed in 1R5F and 3R4F tobaccos, both in the liquid fraction (TPM-F and TPM-T) and in the gas fraction. The effect of the studied catalysts is higher on the full-flavour cigarette than on the ultra-low one. As an example, the reductions observed for $\mathrm{CO}$ and nicotine in TPM-T from 3R4F as a consequence of the SBA- 15 addition were $46 \%$ and $77 \%$, respectively. Thus, although the three checked materials are able to provide noticeable reductions, the best is the one having the higher size of pores (SBA-15).
\end{abstract}

Keywords: Tobacco, Tar, CO, SBA-15, MCM-41, Reduction

\section{Introduction}

Tobacco smoking is a controversial issue of great concern for people and the Departments of Health of many countries (WHO). There is a large amount of data available in the literature regarding the composition of smoke and the influence of the variables in the smoking process. The type of paper and filter (1), the type of tobacco and the smoking regimes (2,3), the cigarette design (1) and the tobacco packing (4), among other variables, are responsible for a wide variation in the results reported that must be carefully analysed in order to obtain adequate conclusions.

The complexities of the chemistry of smoke, where more than 5000 compounds have been identified (5), and of the smoking process, where several processes are overlapped, make this topic especially interesting. During the smoking of a cigarette several mechanisms occur, which cause the generation of tobacco smoke. These mechanisms include: pyrolysis/distillation, combustion, pyrosynthesis, condensation and dilution, which contribute to the formation of the mixture of the forming compounds of tobacco smoke (6,
7). Predominant mechanisms are pyrolysis/distillation, in the range of temperature of around $200-600^{\circ} \mathrm{C}$, and combustion, where the temperature is in the range of around $700-950^{\circ} \mathrm{C}$. These processes generate the so-called mainstream tobacco smoke.

According to Baker and Bishop (5), at least 60 compounds have been identified as toxic and carcinogenic. Potentially harmful smoke constituents have been identified and reviewed by several authors $(8,9)$.

In this context, reference cigarettes play an important role in the research on this topic since they allow the replication and comparison of experiments in different laboratories $(10,11)$. The University of Kentucky is providing such references since 1968. The 1R5F reference tobacco represents an ultra-low tobacco. It delivers approximately $1.67 \mathrm{mg}$ /cigarette of tar, $0.16 \mathrm{mg} /$ cigarette of nicotine and 2.08 TPM mg/cigarette, and $2.95 \mathrm{mg} /$ cigarette using the FTC (Federal Trade Commission) method (http://www2.ca.uky.edu/refcig/), whereas the 3R4F represents a typical American "full flavour" cigarette, yielding typically $9.4 \mathrm{mg} /$ cigarette of tar, $0.7 \mathrm{mg}$ /cigarette of nicotine $11 \mathrm{mg} /$ cigarette of TPM, and $12.0 \mathrm{mg} /$ cigarette of $\mathrm{CO}$, under 
ISO condition and according to the supplier.

The use of aluminosilicates as tobacco additives with different purposes has been described by several authors; as an example, studies describing the use of additives which are added to the filter or directly to tobacco. Meier and Siegmann demonstrated that zeolite catalysts on tobacco provide a good means to reduce the level of toxic compounds in tobacco smoke (12). The use of other aluminosilicates has also been described, as in the case of MCM-48 materials, which have been proposed for reducing polycyclic aromatic hydrocarbons (PAHs) in the mainstream tobacco smoke (13). Other studies describe cigarette filters with carbon nanotubes or with activated carbon and $\mathrm{NaY}$ zeolite $(14,15)$. As an example, $\mathrm{Xu}$ et al. (15) described the use of materials such as zeolites $\mathrm{NaY}$ and ZSM5 in the filter, as well as SBA-15 and MCM-48. These materials are used as selective adsorbents because they favour the removing of specific nitrosamines of tobacco. In the same way, the use of oxide-iron particles for removing $\mathrm{CO}$ has been described by Li and Hajaligol (16). Vesna et al. (17) reported on the effect of the CuZSM5 zeolite on the reduction of PAHs in tobacco smoke, and Lin et al. (18) studied the strong effect of ferric zeolites in reducing the specific tobacco nitrosamines in the tobacco smoke. Deng et al. (19) studied the effect of titanate nanosheets and nanotubes and reported significant reductions of harmful compounds in tobacco. Zeolites, as well as MCM-41, SBA-15 and their modified analogues have also been studied because their ability for efficiently adsorb and catalytically degrade volatile nitrosamines from tobacco due to their special pore structure (20). In this way, Lin et al. (20) have studied the effect of different molecular sieve materials on the elimination of specific tobacco nitrosamines. In that study, these authors tested A, ZSM5 and USY type zeolites as well as mesoporous materials such as MCM-41 and SBA-15, and they concluded that the mesoporous materials were the more effective in reducing such compounds.

According with Lin et al. (20), there are three possible mechanisms for explaining the removal of tobacco smoke nitrosamimes by porous additives. The first one considers that the additive particles are distributed on tobacco rod as "straw spreading on lawn", and their fiber-like morphology permits intercept the particles passed by. The second proposed model suggest that the crystalline catalyst particles, with spherical-like morphologies, could locate on the leaf as "separated stones in lawn", thus with lower ability for the reduction of nitrosamines, that usually rebounds from these particles. Finally, according with the third model, some particles of smoke could be trapped in the cavities of the catalysts, which would be distributed in the tobacco rod "as a rubble". The higher activity of the SBA-15 for intercepting the particulate matter in smoke as compared to crystalline zeolites was mainly attributed to the fiber-like structure morphology of this material leading to a better distribution on the tobacco strands.

Our research group has studied the effect of three commercial zeolites (HUSY, H $\beta$ and HZSM-5) and an own-synthesized Al-MCM-41 catalyst when mixed with a commercial tobacco brand of cigarettes in order to study the modifications in the components of the tobacco smoke (21). We have also studied the effect of Al-MCM-41 on the thermal decomposition behaviour of tobacco (22), as well as the efficiency of solvent extraction for template removal in the synthesis of MCM-41 to be used as tobacco additive for smoke toxicity reduction (23). The results obtained in these works showed that some zeolites and Al-MCM41 were able to reduce to some extent the yields of some known toxic and carcinogenic compounds studied in the mainstream of cigarettes smoke. Especially interesting was the case of the Al-MCM-41 catalyst.

The objective of this work is to study the effect of three catalysts which were prepared in our laboratories, and whose application for reducing tobacco toxicity is protected by a patent $(24,25)$, on two reference tobaccos. Cigarettes prepared with the references directly mixed with the catalysts were smoked under the ISO 3308 smoking conditions. 33 compounds were identified and quantified in the vapour fraction and 84 in the particulate matter. The effect on the yields of these compounds when these catalysts were used as tobacco additives in order to reduce the tobacco harmful effects is also shown in the present work.

\section{Experimental}

\subsection{Catalysts Used}

Three different catalysts were synthesised, and their effect on the yield of several compounds appearing in the mainstream smoke obtained from cigarettes prepared with their mixtures with two reference tobaccos has been studied. The catalysts are mesoporous aluminosilicates and have been prepared according with the standard procedures described in the bibliography. The first catalyst is a SBA-15 with a fiber-like morphology, and has been synthesised as has been proposed by Zhang et al (26) by the reaction of a triblock poly(ethylene

oxide)-b-poly(propyleneoxide)-b-poly(ethylene oxide) copolymer with TEOS in the presence of an aqueous $\mathrm{HCl}$ solution. The obtained SBA-15 (C1 catalyst, according with the nomenclature employed in this work) had a noticeably high pore size in comparison with other mesoporous materials (see Table 1). The other two catalysts (C2 and C3) are MCM-41 samples obtained by different synthesis routes, both of them with sphere-like or granular shapes. C2 catalyst was prepared at room temperature using a polymeric version of ethyl silicate as a source of silica, as was described by Gaydhankar (27), followed by a post-synthesis modification for to obtained the aluminum-containing mesoporous MCM-41 material (28). The third catalyst was obtained according with the sol-gel approach at room temperature proposed by Aguado et al. (29), followed by an ionic interchange step with $\mathrm{Na}^{+}$. The corresponding textural properties and acidity are shown in Table 1. More details about the synthesis can be found in the patents where the use of these catalysts is covered $(24,25)$. 
Table 1. Characteristics of the catalysts

\begin{tabular}{|c|c|c|c|c|}
\hline Catalyst & BET $\operatorname{area}^{1}\left(\mathrm{~m}^{2} / \mathrm{g}\right)$ & Pore volume ${ }^{2}\left(\mathrm{~cm}^{3} / \mathrm{g}\right)$ & 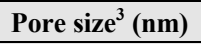 & Acidity $^{4}(\mathrm{mmol} / \mathrm{g})$ \\
\hline C1 (SBA-15) & 757.2 & 1.051 & 6.2 & 0.0 \\
\hline C2 (MCM-41) & 923 & 0.74 & 2.9 & 0.3 \\
\hline C3 (MCM-41) & 1213 & 0.81 & 2.4 & 0.4 \\
\hline
\end{tabular}

1. $\mathrm{N}_{2}$ adsorption isotherms, BET method

2. $\mathrm{N}_{2}$ adsorption isotherms, measured at $\mathrm{P} / \mathrm{P}_{0}=0.995$

3. $\mathrm{N}_{2}$ adsorption isotherms, $\mathrm{BJH}$ method

4. TDP of $\mathrm{NH}_{3}$

\subsection{Reference Cigarettes}

In this work, two reference cigarettes (3R4F and 1R5F) provided by the University of Kentucky (Reference Cigarette Program, College of Agriculture, http://www2.ca.uky.edu/refcig/) have been used in order to check the behaviour of the studied catalysts. The blend specifications for these cigarettes, according to the supplier, are shown in Table 2A and 2B. The percentages are referred to the sum of the masses of the different tobaccos mixed in the cigarette (i.e., Flue cured, Burley, Maryland, Oriental and Reconstituted, for 3R4F). 3R4F (Table 2A) is a "full flavour", filtered, American blended reference cigarette, whereas $1 \mathrm{R} 5 \mathrm{~F}$ (Table 2B) is an ultra-low yield reference cigarette.

Table 2A. Blend summary of $3 R 4 F$ tobacco

\begin{tabular}{ll}
\hline Flue-cured & $35.41 \%$ \\
Burley & $21.62 \%$ \\
Oriental & $12.07 \%$ \\
Maryland & $1.35 \%$ \\
Reconstituted (Schweitzer) & $29.55 \%$ \\
Glycerine & $2.67 \%$ \\
Isosweet (sugar) & $6.41 \%$ \\
\hline
\end{tabular}

*Wet weight basis

Table 2B. Blend summary of 1 R5F tobacco

\begin{tabular}{ll}
\hline Flue-cured & $* 5.75 \%$ \\
Flue-cured puffed & $19.50 \%$ \\
Burley & $42.25 \%$ \\
Burley puffed & $10.50 \%$ \\
Turkish & $7.00 \%$ \\
Reconstituted sheet & $15.00 \%$ \\
Glycerine & $2.80 \%$ \\
Invert sugar & $5.30 \%$ \\
\hline
\end{tabular}

*Wet weight basis

\subsection{Smoking Experiments}

Before performing the smoking experiments, 200 cigarettes of each sample were disassembled and the tobacco, the filter and the paper were weighed separately. The tobacco was tumbled and mixed and then the cigarettes were reassembled in the original tubes. The cigarettes were conditioned for at least $48 \mathrm{~h}$ at $22^{\circ} \mathrm{C}$ and relative humidity of $60 \%$.

Cigarettes were prepared with mixtures of tobacco and catalyst and smoked in a smoking machine described elsewhere $(4,20)$. The results obtained for the composition of the gaseous and condensed products were compared with those corresponding to the standard cigarettes with no catalyst added. In order to obtain similar characteristics of the cigarette packing and conditioning, the reference cigarettes were prepared following the same procedure (i.e.: disassembling the cigarettes and reassembling them as described above).

The smoking machine employed allows five cigarettes to be smoked simultaneously and the pressure of aspiration of the machine was never higher than $1.5 \mathrm{kPa}$. Ten cigarettes were smoked for each experiment. The puff volume was $35 \mathrm{~mL}$, taken for 2.0 seconds, with a puff frequency of 60 seconds, according to the ISO 3308 . The cigarettes were placed in the ports of the smoking machine, ensuring that the ventilating holes were not blocked. The standard butt length, to which cigarettes shall be marked, must be over $23 \mathrm{~mm}$ of length.

The condensable products retained in the filter of the cigarette and in the trap (filter fibre glass, EPM2000 Circles, $47 \mathrm{~mm}$, Acefesa) placed before the Tedlar bag, were extracted with isopropanol (99.9\% purity, Fluka) as solvent and analysed by GC/MS using a HP-5MS column. Before and after each experiment the filter tips and the traps were weighed. The difference has been called TPM-F (total particulate matter condensed in the filters) and TPM-T (total particulate matter condensed in the traps).

The amount of smoked tobacco was determined as the difference between the initial amount of tobacco contained in each cigarette and the amount of tobacco remaining in the butt after the smoking process was finished.

The analysis of the content of $\mathrm{CO}$ and $\mathrm{CO}_{2}$ in the gas-fraction was carried out by GC-TCD using a CTR I column. The rest of non-condensed products were analysed by GC-FID using a GAS-PRO column. Standards gaseous mixtures of $\mathrm{CO}_{2}$ and $\mathrm{CO}$ (Reference 501670) and of gaseous hydrocarbons (References 501816, 22567 and 501662) supplied by Scott Specialty Gases were used to identify and quantify these compounds in the tobacco smoke. The nicotine standard (99.9\% purity) was from Merk. Other compounds such as benzene (Ref. 21803.291) and toluene (Ref. 1.08325.1000) were from VWR while acetaldehyde (Ref. 00070), furan (Ref. 185922) and acetonitrile (Ref. 34967) were supplied by Sigma. 33 and 84 compounds were identified and analysed in the fraction collected in the Tedlar bags and in the TPM (both, TPM-F and TPM-T), respectively. The analysis and quantification of the compounds have been carried as described elsewhere (4). Standard deviations lower than $20 \%$ were obtained for all the compounds analysed. 


\section{Results and Discussion}

\subsection{Preliminary Analysis}

Table 3 shows the number of puffs, the actual weight percentage of catalyst mixed with tobacco, the amount of smoked tobacco in the smoking runs and the total particulate matter condensed in filters and traps (TPM-F and TPM-T), both expressed as milligrams per gram of smoked tobacco. TPM-F and TPM-T have been chemically analysed to adequately evaluate the activity of the catalyst and to know the actual change in quantity and composition of the total smoke generated. Table 3 reflects that, in all cases, the addition of the studied catalysts reduces the yield of TPM, even though in some cases the number of puffs increases as does the amount of tobacco smoked. Mixtures of 1R5F and C3 have not been considered because, as demonstrated in the following sections, the results obtained showed that $\mathrm{C} 1$ is better than $\mathrm{C} 2$ and $\mathrm{C} 3$ in order to reduce tobacco toxicity, and the effect of the catalysts is more noticeable when they are mixed with the full flavour $3 \mathrm{R} 4 \mathrm{~F}$ than with the ultra-low $1 \mathrm{R} 5 \mathrm{~F}$.

Table 3. Number of puffs, amount of catalysts added, amount of smoked tobacco, TPM-F, TPM-T and TPM-F+TPM-T for the different experiments

\begin{tabular}{lllllll}
\hline Sample & $\begin{array}{l}\text { Number of } \\
\text { puffs }\end{array}$ & $\begin{array}{l}\text { Catalyst } \\
(\%, \mathbf{w} / \mathbf{w})\end{array}$ & Smoked tobacco $(\mathbf{g})$ & $\begin{array}{l}\text { TPM-F } \\
(\mathbf{m g} / \mathbf{g} \text { smoked tobacco) }\end{array}$ & $\begin{array}{l}\text { TPM-T } \\
(\mathbf{m g} / \mathbf{g} \text { smoked tobacco) }\end{array}$ & $\begin{array}{l}\text { TPM-F + } \\
\text { TPM-T (mg/g smoked tobacco) }\end{array}$ \\
\hline 1R5F & 7 & 0.0 & 6.19 & 25.2 & 3.56 & 28.8 \\
1R5F+C1 & 8 & 5.6 & 6.32 & 9.34 & 0.99 & 10.3 \\
1R5F+C2 & 8 & 5.2 & 6.32 & 18.4 & 3.03 & 21.5 \\
3R4F & 9 & 0.0 & 6.78 & 29.6 & 11.5 & 41.0 \\
3R4F+C1 & 9 & 5.6 & 6.64 & 10.4 & 2.26 & 12.7 \\
3R4F+C2 & 9.7 & 5.6 & 6.44 & 17.5 & 5.70 & 23.1 \\
3R4F+C3 & 10 & 5.8 & 6.47 & 21.1 & 4.98 & 26.0 \\
\hline
\end{tabular}

Table 4 shows the amounts of nicotine, $\mathrm{CO}$ and tar reported by the supplier (11, http://www2.ca.uky.edu/refcig/) and that obtained in the present work. The values are quite comparable, especially when taking into account that the cigarettes smoked in the present work have been emptied and refilled following the same procedure as in the case of the cigarettes including the catalysts, in order to have an adequate reference to establish the effect of the catalyst. Moreover, the butt length is different in both cases $(35 \mathrm{~mm}$ in the reported results for reference cigarettes and $23.5 \mathrm{~mm}$ in the present work), although the number of puffs is the same. These results enhance the importance and the need for treating the reference cigarettes in exactly the same way as the catalyst added cigarettes.

Table 4. Nicotine, carbon monoxide and tar yields in the mainstream smoke of the reference cigarettes $1 R 5 F$ and $3 R 4 F$ reported by the supplier and obtained in the present work

\begin{tabular}{llll}
\hline Sample & Nicotine (mg/cigarette) & CO (mg/cigarette) & Tar (mg/cigarette) \\
\hline 1R5F (Supplier) & 0.16 & 2.95 & 1.67 \\
1R5F & 0.14 & 4.30 & 1.47 \\
3R4F (Supplier) & 0.73 & 12.0 & 9.40 \\
3R4F & 0.65 & 11.0 & 7.40 \\
\hline
\end{tabular}

As pointed out above, according to Table 3, the amount of TPM-F and TPM-T obtained is lowered when both standard tobaccos are mixed with the catalysts studied in this work. The percentages of reduction obtained $[\%$ reduction $=100 \times$ (yield obtained with no catalyst-yield obtained with catalyst addition)/(yield obtained with no catalyst)] for total TPM in the case of the $1 \mathrm{R} 5 \mathrm{~F}$ cigarette are in the range of $25-64 \%$. Moreover, $\mathrm{C} 1$ permits to obtain higher reductions than $\mathrm{C} 2$ and higher for TPM-T than for TPM-F, reaching values of $72 \%$ and $63 \%$, respectively. In the case of the $3 \mathrm{R} 4 \mathrm{~F}$ cigarette, the results obtained are better, thus showing the great influence of the tobacco characteristics on the behaviour of the catalysts, and the need for carrying out specific studies in each particular case. As can be seen, the percentages of total TPM reduction provided by the catalysts are in the range of $36-69 \%$, and they are also higher for TPM-T (50-80\%) than for TPM-F, and are also the highest for $\mathrm{C} 1(65-80 \%)$. The reductions obtained when $\mathrm{C} 3$ was added are lower than that obtained with $\mathrm{C} 2$ for TPM-F and total TPM, and slightly higher for TPM-T. Thus, the case of catalyst $\mathrm{C} 1$ is particularly interesting because it permits to obtain very high reductions in TPM, especially in TPM-T for both studied references (i.e., $80 \%$ for $3 \mathrm{R} 4 \mathrm{~F}$ and $72 \%$ for $1 \mathrm{R} 5 \mathrm{~F}$ ). As Table 3 reflects, the amount of particulate matter retained by the filters is very similar for both types of reference tobaccos, though the main difference is in the amount retained in the traps. As expected, that corresponding to the $1 \mathrm{R} 5 \mathrm{~F}$ is much lower as corresponds to an ultra-light tobacco.

\subsection{Analysis of the Vapour Phase}

Tables A1 and A2 of the Appendix show the yield of the 33 compounds identified and quantified in the gaseous fraction obtained from the experiments corresponding to the $1 \mathrm{R} 5 \mathrm{~F}$ and 3R4F systems, respectively (i.e., different mixtures of tobacco 
+ catalysts, and two reference tobaccos). Figures 1, 2 and 3 show the results corresponding to the major compounds.

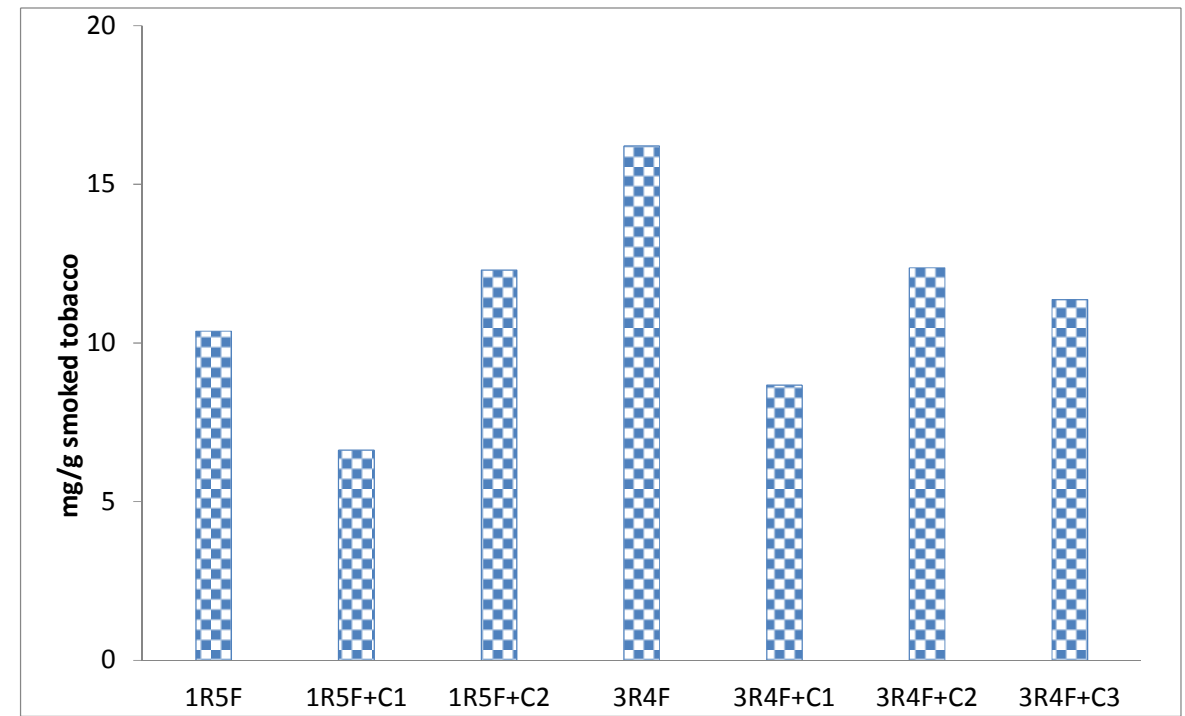

Figure 1. Yield of CO from the reference tobaccos in the presence and in the absence of catalysts

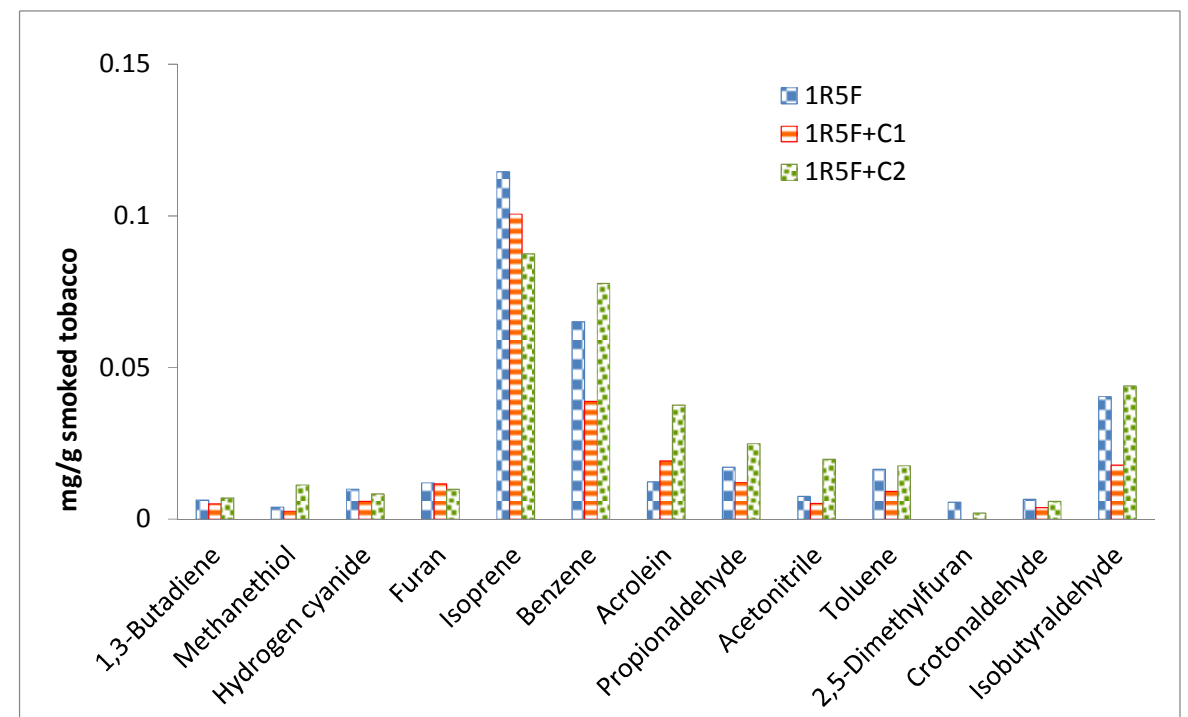

Figure 2. Yield of some selected compounds of gaseous fraction for the reference tobacco $1 R 5 F$ and its mixtures with different catalysts

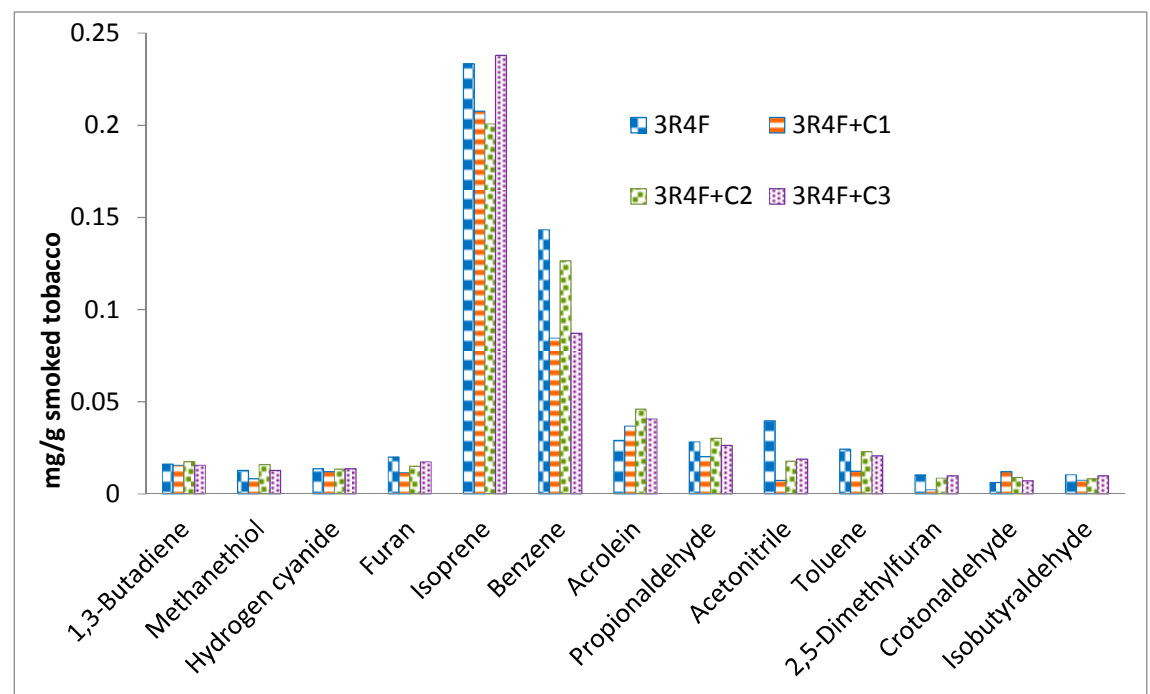

Figure 3. Yield of some selected compounds of gaseous fraction for the reference tobacco $3 R 4 F$ and its mixtures with different catalysts 
According to Figure 1, $\mathrm{C} 1$ is the most effective catalyst for reducing the yield of $\mathrm{CO}$ from both reference tobaccos, with around $36 \%$ of reduction in the case of $1 \mathrm{R} 5 \mathrm{~F}$ and $46 \%$ in the case of 3R4F. The catalyst $\mathrm{C} 2$ causes a slight increase (around $18 \%$ ) in the yield of CO obtained from 1R5F and a decrease $(23 \%)$ in the yield from $3 \mathrm{R} 4 \mathrm{~F}$, whereas $\mathrm{C} 3$ decreases the yield of $\mathrm{CO}$ from $3 \mathrm{R} 4 \mathrm{~F}$ by around $30 \%$. These results are in good agreement with those shown in Table 3 for the TPM yields, that suggested that $\mathrm{C} 1$ is the best catalyst in order to globally reduce the yields of toxic and carcinogenic compounds, and that the effect of the studied catalyst is more noticeable on the American full flavour $3 \mathrm{R} 4 \mathrm{~F}$ than on the ultra-low tobacco $1 \mathrm{R} 5 \mathrm{~F}$. The effect of the catalysts considered on the yield of CO obtained when cigarettes are smoked is an interesting issue because $\mathrm{CO}$ is one of the regulated products in order to control the adverse and harmful consequences of smoking tobacco.

As can be seen in Figures 2 and 3, generally, the presence of $\mathrm{C} 1$ significantly reduces the yield of all the compounds present in the gaseous fraction from both $1 \mathrm{R} 5 \mathrm{~F}$ and $3 \mathrm{R} 4 \mathrm{~F}$, except acrolein, which seems to be increased in the presence of the studied catalysts, especially in the case of 1R5F. The yield of crotonaldehyde from 3R4F also shows a slight increase. The global decrease in the compounds analysed in the gases as a consequence of the $\mathrm{C} 1$ addition is around $27 \%$ and $40 \%$ for $1 \mathrm{R} 5 \mathrm{~F}$ and $3 \mathrm{R} 4 \mathrm{~F}$, respectively. This catalyst significantly decreases the yields of benzene and toluene and, in the case of $1 \mathrm{R} 5 \mathrm{~F}$, isobutyraldehyde. In the case of 3R4F, a noticeable decrease for acetonitrile can also be appreciated. The effect of $\mathrm{C} 2$ in the mainstream smoke from $1 \mathrm{R} 5 \mathrm{~F}$ is not very significant and produces only slight variations of all the compounds analysed, with an increase of around $13 \%$ in the global gases, which can be related with the increase in methanethiol, benzene, acrolein, propionaldehyde and acetonitrile. Nevertheless, the effect of $\mathrm{C} 2$ on the mainstream smoke from $3 \mathrm{R} 4 \mathrm{~F}$ is more significant, with a reduction of around $22 \%$ of the global gases, associated with reductions in most of the compounds, despite that some of them show almost no variation and others, such as acrolein, are increased. The effect of $\mathrm{C} 3$ on the mainstream smoke from $3 \mathrm{R} 4 \mathrm{~F}$ is worse than that of $\mathrm{C} 1$ and $\mathrm{C} 2$, with a global reduction of around $10 \%$, which is dominated by the decrease of benzene and acetonitrile and the increase of isoprene and acrolein. The other compounds are affected to a very low extent. Also of great interest is the case of benzene, which shows noticeable reductions as a consequence of the presence of $\mathrm{C} 1$ (with $1 \mathrm{R} 5 \mathrm{~F}$ and $3 \mathrm{R} 4 \mathrm{~F}$ ) and $\mathrm{C} 3$ (with $3 \mathrm{R} 4 \mathrm{~F}$ ) but, in the presence of $\mathrm{C} 2$ this compound shows a small decrease for $3 \mathrm{R} 4 \mathrm{~F}$ or even an increase in the case of $1 \mathrm{R} 5 \mathrm{~F}$.

According to the previous results, it seems apparent that the large pore size of the $\mathrm{C} 1$ catalyst and, consequently, the high pore volume are the more relevant characteristics for favouring the reduction of the yield of different compounds analysed in the gaseous fraction of the mainstream smoke. Thus, this catalyst is the most effective despite its lower surface area and null acidity in front of the other catalysts, which show higher surface areas, especially C3, and acidic properties. These results are very interesting because previous studies showed that several materials with chemical and textural properties similar to that of $\mathrm{C} 2$ and $\mathrm{C} 3$ were able to reduce tobacco toxicity in a significant way (21). In this way, $\mathrm{C} 1$ would be an even more efficient additive for this purpose.

\subsection{Particulate Matter}

The main fraction of the smoke is formed by condensable products, which are the main constituents of the particulate matter. As explained in the "experimental" section, these condensable compounds are retained in the filters of the cigarettes and in a trap located before the Tedlar bag for the gas collection, yielding the total particulate matter retained in the filters (TPM-F), in the traps (TPM-T). The corresponding yields were presented and discussed in Table 3. In good agreement with the results obtained for the gaseous fraction, $\mathrm{C} 1$ produces the highest percentages of reduction, and the catalysts are more effective over 3R4F than over 1R5F. In this section, the results obtained when these condensable products -in the present work so-called liquids retained- have been extracted with isopropanol and analysed by GC/MS are presented and discussed.

84 compounds have been identified and quantified in these condensable products. The results corresponding to TPM-F and TPM-T from 1R5F and its mixtures with $\mathrm{C} 1$ and $\mathrm{C} 2$ are shown in Tables A3 and A4 of the Appendix. In order to facilitate the interpretation and comparison of the results, these compounds have been grouped by families, according to their chemical functionality, in the same manner as described elsewhere (21). Thus, the families considered are the following: nitrogenous, carbonyls, phenolics, epoxies, aromatics, aliphatics and others. Tables 5 and 6 show the yields obtained for such families, according to Tables A3 and A4. In order to simplify the tables, compounds which were below the detection limit of the analytical equipment have been omitted. The complete list of the 84 identified compounds is shown in Table A5, where the results for TPM-F from the systems including the $3 \mathrm{R} 4 \mathrm{~F}$ reference are presented. As seen, the first interesting observation is that the number of compounds retained in the filters is higher than that retained in the traps and, moreover the yields obtained in the filters are also higher. This behaviour can be observed for both types of systems, i.e., that involving $1 \mathrm{R} 5 \mathrm{~F}$ and $3 \mathrm{R} 4 \mathrm{~F}$, respectively.

Table 5. Yield of different families of compounds analysed in the TPM-F of the mainstream smoke of systems involving 1R5F tobacco

\begin{tabular}{llll}
\hline mg compound/g smoked tobacco & 1R5F & 1R5F+C1 & 1R5F+C2 \\
\hline Nitrogenous & 1.91 & 1.07 & 1.63 \\
Carbonylic & 0.27 & 0.09 & 0.20 \\
Epoxy & 0.03 & 0.01 & 0.02 \\
Aromatic & 0.02 & $<0.01$ & 0.01 \\
Others & 0.06 & 0.02 & 0.03 \\
Phenolic & 0.24 & 0.06 & 0.14 \\
Aliphatic & 0.25 & 0.13 & 0.20 \\
\hline
\end{tabular}


Table 6. Yield of different families of compounds analysed in the TPM-T of the mainstream smoke of systems involving 1R5F tobacco

\begin{tabular}{llll}
\hline mg compound/g smoked tobacco & $\mathbf{1 R 5 F}$ & $\mathbf{1 R 5 F}+\mathbf{C 1}$ & $\mathbf{1 R 5 F}+\mathbf{C 2}$ \\
\hline Nitrogenous & 1.91 & 1.07 & 1.63 \\
Carbonylic & 0.27 & 0.09 & 0.20 \\
Epoxy & 0.03 & 0.01 & 0.02 \\
Aromatic & 0.02 & $<0.01$ & 0.01 \\
Others & 0.06 & 0.02 & 0.03 \\
Phenolic & 0.24 & 0.06 & 0.14 \\
Aliphatic & 0.25 & 0.13 & 0.20 \\
\hline
\end{tabular}

Figures 4 and 5 show the percentages of reduction (calculated as previously described) obtained for the different families of compounds considered, in the case TPM-F and TPM-T, respectively, when mixtures of $\mathrm{C} 1$ and $\mathrm{C} 2$ with the reference tobacco $1 \mathrm{R} 5 \mathrm{~F}$ were smoked. As can be seen, $\mathrm{C} 1$ permits to obtain higher reductions than $\mathrm{C} 2$ for all the considered families, both in TPM-F and TPM-T. Moreover, generally, the percentages de reductions obtained for each family are higher in TPM-T than in TPM-F. In fact, the average reduction obtained for the different families in TPM-F is around $63 \%$ in the presence of $\mathrm{C} 1$, and $32 \%$ in presence of $\mathrm{C} 2$, and the corresponding values for TMP-T are around $89 \%$ and $35 \%$, respectively.

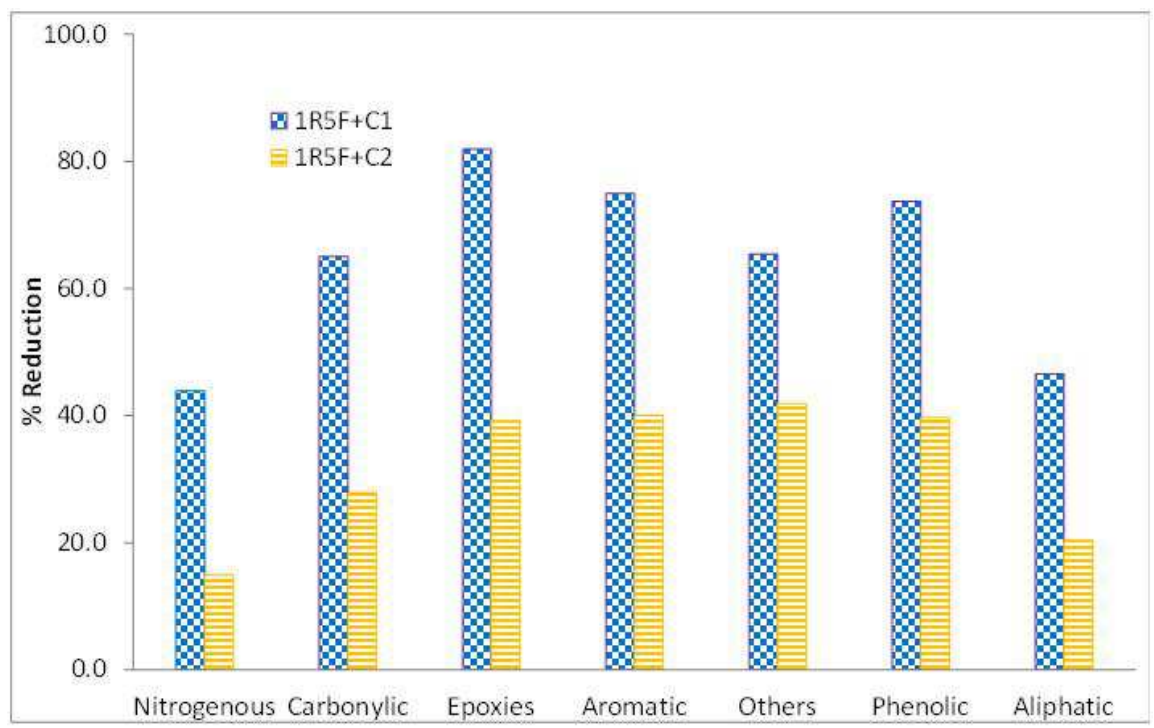

Figure 4. Percentages of reduction of several families of compounds appearing in TPM-F as consequence of the addition of C1 and C2 as catalysts



Figure 5. Percentages of reduction of several families of compounds appearing in TPM-T as consequence of the addition of C1 and C2 as catalysts

The previous results indicate that, as was pointed out from the gaseous fraction, $\mathrm{C} 1$ is able to reduce the appearance of most of the compounds analysed in the condensable products of the mainstream smoke obtained from $1 \mathrm{R} 5 \mathrm{~F}$ cigarettes, and that it is better than $\mathrm{C} 2$ at reducing the yield of these compounds. In this case, it also seems that the main property that conducts the ability for the studied solid materials is the size and volume of pores, which is much more significant than the acidity.

Tables A5 and A6 of the Appendix show the results corresponding to the yield of the different compounds analysed in TPM-F and TPM-T in the case of systems involving the $3 \mathrm{R} 4 \mathrm{~F}$ reference tobacco. As mentioned above, Table A5 contains the complete list of the 84 identified 
compounds. The same grouping in families as in the previous case has been done, and the results obtained are presented in Tables 7 and 8 . The percentages of reduction obtained for each family as a consequence of the addition of catalysts have been calculated and are graphically shown in Figures 6 and 7.

Table 7. Yield of different families of compounds analysed in the TPM-F of the mainstream smoke of systems involving $3 R 4 F$ tobacco

\begin{tabular}{lllll}
\hline $\begin{array}{l}\text { mg compound/g } \\
\text { smoked tobacco }\end{array}$ & 3R4F & 3R4F+C1 & 3R4F+C2 & 3R4F+C3 \\
\hline Nitrogenated & 1.372 & 0.711 & 1.226 & 1.415 \\
Carbonylic & 0.280 & 0.102 & 0.194 & 0.354 \\
Epoxy & 0.023 & 0.006 & 0.015 & 0.008 \\
Aromatic & 0.031 & 0.012 & 0.024 & 0.033 \\
Others & 0.039 & 0.033 & 0.048 & 0.075 \\
Phenolic & 0.228 & 0.073 & 0.160 & 0.277 \\
Aliphatic & 0.219 & 0.099 & 0.149 & 0.233 \\
\hline
\end{tabular}

Table 8. Yield of different families of compounds analysed in the TPM-T of the mainstream smoke of systems involving $3 R 4 F$ tobacco

\begin{tabular}{lllll}
\hline $\begin{array}{l}\text { mg compound/g } \\
\text { smoked tobacco }\end{array}$ & 3R4F & 3R4F+C1 & 3R4F+C2 & 3R4F+C3 \\
\hline Nitrogenated & 1.028 & 0.229 & 0.665 & 0.795 \\
Carbonylic & 0.046 & 0.003 & 0.012 & 0.023 \\
Epoxy & 0.004 & 0.001 & 0.002 & 0.003 \\
Aromatic & 0.016 & 0.000 & 0.001 & 0.000 \\
Others & 0.019 & 0.002 & 0.009 & 0.017 \\
Phenolic & 0.073 & 0.003 & 0.016 & 0.050 \\
Aliphatic & 0.146 & 0.018 & 0.058 & 0.103 \\
\hline
\end{tabular}

As observed for the reference 1R5F, the yields of the different compounds analysed in the condensable fraction of the mainstream smoke from $3 \mathrm{R} 4 \mathrm{~F}$ are higher in the filters than in the traps. As expected, the numbers of detected compounds as well as the corresponding yields are higher in the case of the 3R4F full-flavour tobacco than in the ultra-low 1R5F. The behaviour of the catalysts is also in agreement with the previous statements, and $\mathrm{C} 1$ produces higher reductions than $\mathrm{C} 2$, despite its absence of acidity. The global reductions obtained in the case of TPM-F are $52 \%$ and $17 \%$, in the presence of $\mathrm{C} 1$ and $\mathrm{C} 2$, whereas in the presence of $\mathrm{C} 3$ a slight increase of $9 \%$ is observed. In the case of the TMF-T, these reductions are at around $81 \%, 43 \%$ and $26 \%$ (values calculated from Tables A5 and A6) respectively.

With respect to TPM-F, if the behaviour of the catalyst from the point of view of the different families of compounds (Figure 6 and Table 13) is analysed, it can be seen that, with the only exception of the group of "Others", the reductions provided by $\mathrm{C} 1$ are in the range of $48-74 \%$, and for $\mathrm{C} 2$ in the range of $11-35 \%$. Moreover, the effect of each catalyst is quite different depending on the family considered. Thus, C1 mainly reduces the group of epoxy compounds (at around $74 \%$ ), followed by carbonyl, aromatic and phenolic (61-68\%), aliphatic (55\%) and nitrogenous compounds (48\%), whereas the reductions obtained with $\mathrm{C} 2$ are ordered as follows: epoxies (35\%), carbonylic, aliphatic and phenolic (30-32\%), aromatics (23\%) and nitrogenous (11\%). The group of "Other" compounds shows a decrease of $15 \%$ in the presence of $\mathrm{C} 1$ and an increase of $23 \%$ in the presence of $\mathrm{C} 2$. With $\mathrm{C} 3$ and 3R4F all the families are increased in TPM-F, with the only exception of epoxies, which are reduced at around $65 \%$.

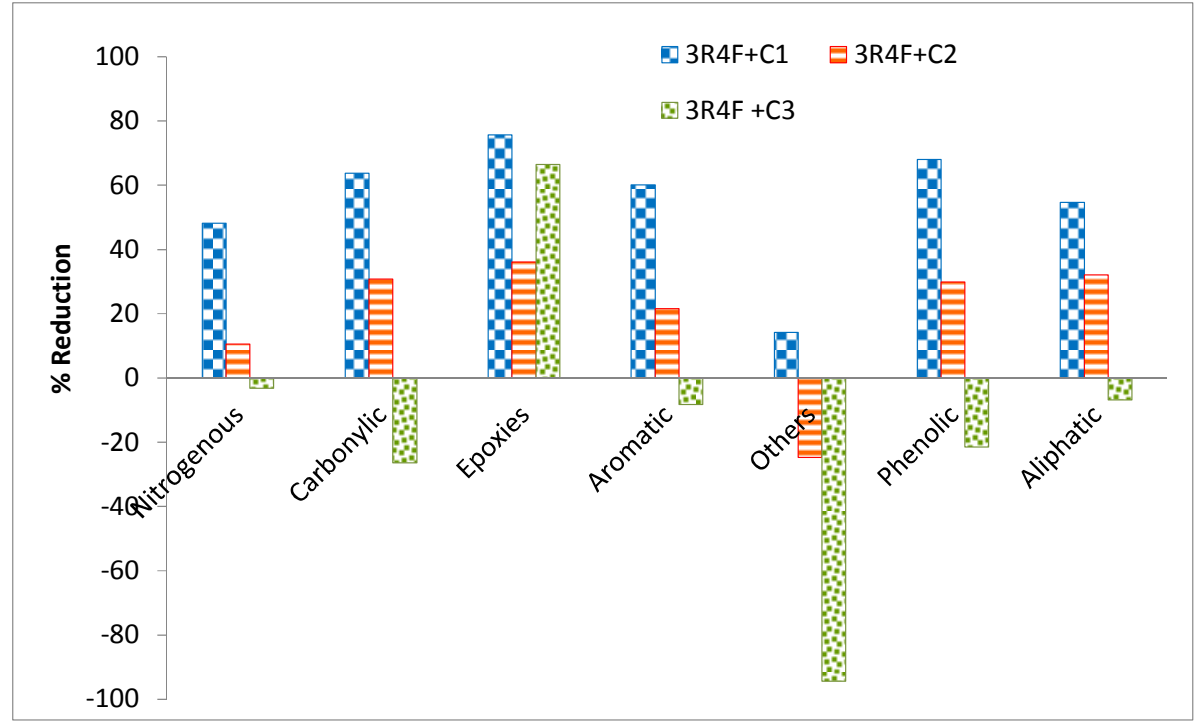

Figure 6. Percentages of reduction of several families of compounds appearing in TPM-F as consequence of the addition of C1, C2 and C3 as catalysts 


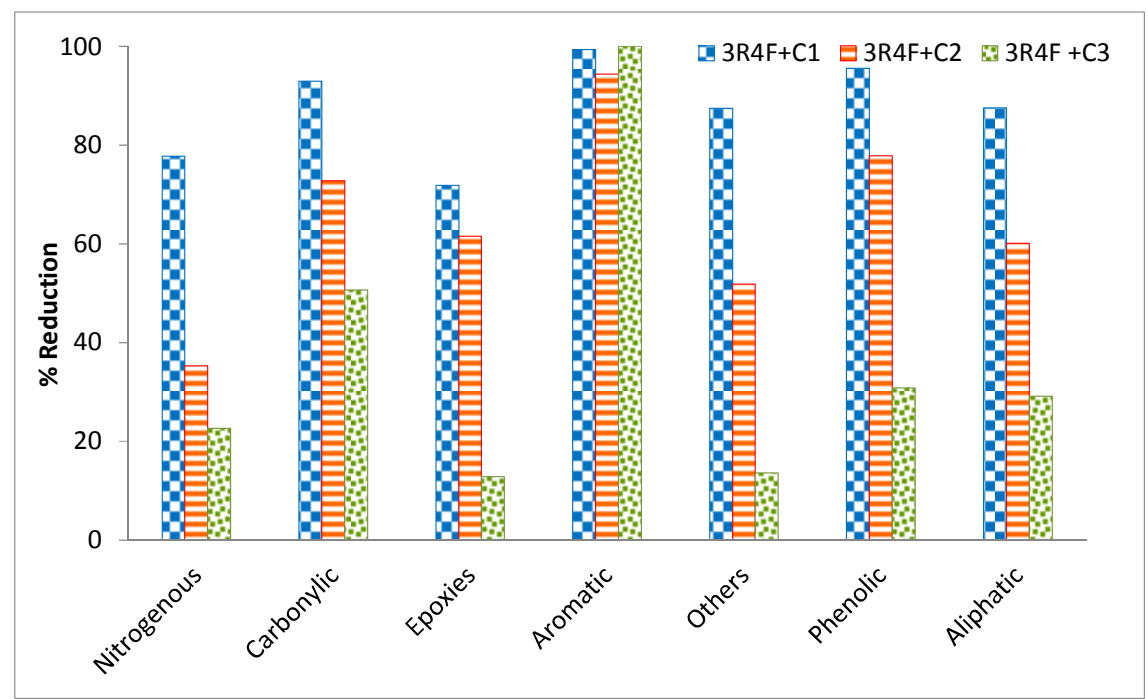

Figure 7. Percentages of reduction of several families of compounds appearing in TPM-T as consequence of the addition of C1, C2 and C3 as catalysts

Noticeable differences have been found between the effect of the studied catalyst on the yields of compounds obtained in TPM-F and in TPM-T. Effectively, according to Table 8 and Figure 7, different than the behaviour observed for TPM-F, the three considered catalysts contribute to decrease the yield of all the families of compounds appearing in the TPM-T. Moreover, the percentages of reduction obtained are very interesting for all the families (in the range of $75-100 \%, 35-94 \%$ and $11-100 \%$ for $\mathrm{C} 1, \mathrm{C} 2$ and $\mathrm{C} 3$, respectively). As in the previous cases, the best catalyst is $\mathrm{C} 1$, followed by $\mathrm{C} 2$ and by $\mathrm{C} 3$. Nevertheless, in this case, $\mathrm{C} 3$ is also capable of provide interesting reductions. The group of aromatics is the one showing the highest reductions in the presence of the three catalysts. As pointed out, very high reductions are also obtained for the other families when $\mathrm{C} 1$ is added, the lowest (75\%) being for the group of epoxies. The reduction of aromatics by the effect of $\mathrm{C} 2$ is around $94 \%$, and the reduction for the others families ranges between $50 \%$ and $78 \%$, with the only exception of nitrogenous, which shows with this catalyst the lowest reduction (35\%). The results obtained in the presence of $\mathrm{C} 3$ are quite different, with practically a $100 \%$ of reduction of aromatics, followed by carbonyl compounds $(50 \%)$ The rest of families are in the range of $11-32 \%$ (in this case, then nitrogenous compounds are reduced by around $23 \%$ ).

The reductions of nicotine as a consequence of the $\mathrm{C} 1, \mathrm{C} 2$ and $\mathrm{C} 3$ addition are, respectively, around $47 \%, 10 \%$ and $-2 \%$ (i.e., increase of $2 \%$ ) in TMP-F and $77 \%, 34 \%$ and $22 \%$ in TPM-T.

The results obtained agree with the previously commented great influence of the pore size. Effectively, in all the considered cases, the highest pore size SBA-15 (C1) is the catalyst providing the highest reductions. Moreover, when both mesoporous MCM-41 (C2 and C3) are compared, the one with higher pore size $(\mathrm{C} 2)$ also seems to be better, despite its lower acidity. The great influence (i.e., the higher reductions) of the studied catalyst on TPM-T than on TPM-F is also very interesting because TPM-T is the most interesting fraction if we consider that it is the one that is inhaled by active smokers.

A remarkable aspect that can be observed in Tables A3, A4,
A5 and A6 is the way compounds are delivered between the filter and the trap according to their retention time, an aspect already observed in previous articles (4). Compounds with low retention time (i.e., compounds with relatively low molecular weight) are higher in the filters than in the traps, while the very opposite is true for the heaviest compounds.

\section{Conclusions}

In this work the ability of three mesoporous aluminosilicate solids to reduce the amount of the different compounds appearing in the mainstream smoke from two reference cigarettes has been studied. The results obtained reveal that these materials permit to decrease the yields of most of the analysed compounds, both in the gaseous and in the liquid fraction of the mainstream smoke. The material with the highest pore size (SBA-15 or C1 according with the employed nomenclature) seems to provide higher reductions than the MCM-41 samples, $\mathrm{C} 2$ and $\mathrm{C} 3$, with significant lower pore size $\mathrm{C} 2$, with higher pore size and lower BET area and acidity than $\mathrm{C} 3$ also seems to be better than $\mathrm{C} 3$, thus enhancing the importance of the pore size role. In general, higher percentages of reduction have been obtained for the full-flavour reference cigarette $3 \mathrm{R} 4 \mathrm{~F}$ than for the ultra-low reference tobacco 1R5F. Higher reductions have also been obtained for TPM-T than for TPM-F. Thus, the most spectacular results correspond to the cigarettes prepared with a mixture of $\mathrm{C} 1$ and $3 \mathrm{R} 4 \mathrm{~F}$ tobacco. Thus, as an example, for this system, the following percentages of reduction have been obtained:

- Total TPM (TPM-F+TPM-T): $69 \%$

- Global yield of gases: $40 \%$

- CO: $47 \%$

- Chemical families in TPM-F: nitrogenous (48\%), carbonyls (64\%), epoxies (74\%), aromatics (61\%), other compounds (15\%), phenolics (68\%) and aliphatics $(55 \%)$

- Chemical families in TPM-T: nitrogenous (78\%), carbonyls $(93 \%)$, epoxies $(75 \%)$, aromatics $(100 \%)$, 
other compounds (89\%), phenolics (96\%) and aliphatics $(88 \%)$

- Nicotine: $77 \%$

Reductions obtained in the yields of $\mathrm{CO}$ in the case of tobacco $3 \mathrm{R} 4 \mathrm{~F}$, were $47 \%$ for the $\mathrm{C} 1$ catalyst, $24 \%$ for the $\mathrm{C} 2$ catalyst and $30 \%$ for the $\mathrm{C} 3$ catalyst. In the case of the ultra-light $1 \mathrm{R} 5 \mathrm{~F}$ tobacco, only the $\mathrm{C} 1$ catalyst was capable of reducing the evolution of this compound. The total amount of the gaseous fraction for $3 \mathrm{R} 4 \mathrm{~F}$ was reduced $40 \%$ when catalyst $\mathrm{C} 1$ was used, $22 \%$ in presence of $\mathrm{C} 2$ and $10 \%$ in presence of C3. When smoking 1R5F tobacco, the total amount of the gaseous fraction was $27 \%$ reduced in the presence of $\mathrm{C} 1$. The effect of C2 is not very significant and produces only slight variations of all the compounds analysed. Global gases are increased around 13 with the $\mathrm{C} 2$.

The total amount of TPM in the two tobaccos analysed, $1 \mathrm{R} 5 \mathrm{~F}$ and $3 \mathrm{R} 4 \mathrm{~F}$, was reduced over $60 \%$ in the presence of $\mathrm{C} 1$. Others catalysts also reduce this fraction, though to a lesser extent. When tobacco $1 \mathrm{R} 5 \mathrm{~F}$ is smoked, all families in TPM-F and in TPM-T are reduced in the presence of the two catalysts, being the effect of $\mathrm{C} 1$ more remarkable. When tobacco 3R4F is smoked, the yields of all families in TPM-T are reduced in the presence of the three catalysts, all the families in TPM-F are reduced by $\mathrm{C} 1$ and $\mathrm{C} 2$, with the only exception of the group of others in the $3 \mathrm{R} 4 \mathrm{~F}+\mathrm{C} 2$ system, and all the families are increased by $\mathrm{C} 3$, with the only exception of epoxies, which are decreased. It has been observed that in TPM-F, the compounds with lower molecular height are retained in higher proportion, contrarily to the effect observed in the traps, where the compounds with higher molecular weight are retained in greater extent.

In conclusion, catalyst $\mathrm{C} 1$ (i.e., SBA-15) is the one providing a larger reduction of the yields of the majority of the compounds analysed, and for all the groups of compounds considered.

These results agree with the data reported by Lin et al. (20), that obtained that SBA-15 allows higher reduction of TPM than MCM-41 when these materials are used as cigarette additives, in spite of the yields obtained are different due to the differences between the tobacco rod characteristics and the experimental conditions for the smoking process simulation. These authors suggested that the main mechanism involved in the tobacco nitrosamines reduction by mesoporous silica is the filtration of the particles in smoke, due to the fiber-like morphology of the catalyst. The SBA-15 used in the present work has a similar fiber-like morphology as compared to the spherical one of the other catalysts tested. In addition, this catalyst is the one having the largest pore size and pore volume, both characteristics contributing to increase the reduction effect.

\section{Acknowledgements}

Financial support for this investigation has been provided by the Spanish "Secretaría de Estado de Investigación" del Ministerio de Ciencia e Innovación (CTQ2008-01023) and Generalitat Valenciana (PROMETEO/2012/015).

\section{Appendix}

Table A1. Yield of different compounds analysed in the gaseous fraction of the mainstream smoke of systems involving $1 R 5 F$ tobacco. Yields are expressed in mg of compound/g of smoked tobacco

\begin{tabular}{|c|c|c|c|}
\hline Compound & 1R5F & $1 \mathrm{R} 5 \mathrm{~F}+\mathrm{C} 1$ & $1 \mathrm{R} 5 \mathrm{~F}+\mathrm{C} 2$ \\
\hline $\mathrm{CO}$ & 10.4 & 6.62 & 12.3 \\
\hline $\mathrm{CO}_{2}$ & 34.4 & 26.2 & 38.4 \\
\hline Methane & 0.61 & 0.39 & 0.66 \\
\hline Ethane & 0.27 & 0.17 & 0.27 \\
\hline Ethylene & 0.12 & 0.089 & 0.14 \\
\hline Propane & 0.13 & 0.085 & 0.13 \\
\hline Propene & 0.13 & 0.087 & 0.14 \\
\hline Iso-butane & 0.013 & 0.0083 & 0.015 \\
\hline Chloromethane & 0.024 & 0.015 & 0.024 \\
\hline Butane & 0.043 & 0.026 & 0.039 \\
\hline 1-Butene & 0.032 & 0.020 & 0.031 \\
\hline 1,3-Butadiene & 0.0063 & 0.0050 & 0.0070 \\
\hline Isobutene & 0.035 & 0.021 & 0.031 \\
\hline cis-2-Butene & 0.027 & 0.015 & 0.024 \\
\hline Pentane & 0.012 & 0.0069 & 0.011 \\
\hline Methanethiol & 0.0040 & 0.0026 & 0.011 \\
\hline Hydrogen cyanide & 0.0099 & 0.0059 & 0.0080 \\
\hline 1-Pentene & 0.010 & 0.0059 & 0.0090 \\
\hline
\end{tabular}




\begin{tabular}{llll}
\hline Compound & $\mathbf{1 R 5 F}$ & $\mathbf{1 R 5 F + C 1}$ & $\mathbf{1 R 5 F + C 2}$ \\
\hline Furan & 0.012 & 0.012 & 0.010 \\
Isoprene & 0.11 & 0.10 & 0.088 \\
Hexane & 0.0029 & 0.0034 & 0.0020 \\
1-Hexene & 0.0076 & 0.0048 & 0.0075 \\
Benzene & 0.065 & 0.039 & 0.078 \\
Acetaldehyde & 0.36 & 0.17 & 0.35 \\
Acrolein & 0.012 & 0.019 & 0.038 \\
Propionaldehyde & 0.017 & 0.012 & 0.025 \\
Acetonitrile & 0.0075 & 0.0052 & 0.020 \\
Toluene & 0.016 & 0.0091 & 0.018 \\
2,5-Dimethylfuran & 0.0056 & 0.000 & 0.0020 \\
Crotonaldehyde & 0.0065 & 0.0038 & 0.0059 \\
Isobutyraldehyde & 0.040 & 0.018 & 0.044 \\
Sum & 86.6 & 52.0 & 67.4 \\
\hline
\end{tabular}

Table A2. Yield of different compounds analysed in the gaseous fraction of the mainstream smoke of systems involving $3 R 4 F$ tobacco. Yields are expressed in mg of compound/g of smoked tobacco

\begin{tabular}{|c|c|c|c|c|}
\hline Compound & 3R4F & $3 \mathrm{R} 4 \mathrm{~F}+\mathrm{C} 1$ & $3 \mathrm{R} 4 \mathrm{~F}+\mathrm{C} 2$ & $3 \mathrm{R} 4 \mathrm{~F}+\mathrm{C} 3$ \\
\hline $\mathrm{CO}$ & 16.2 & 8.67 & 12.4 & 11.4 \\
\hline $\mathrm{CO}_{2}$ & 66.3 & 40.4 & 51.0 & 63.4 \\
\hline Methane & 1.20 & 0.86 & 1.15 & 1.04 \\
\hline Ethane & 0.49 & 0.37 & 0.47 & 0.43 \\
\hline Ethylene & 0.25 & 0.19 & 0.26 & 0.24 \\
\hline Ethyne & 0.027 & 0.025 & 0.040 & 0.032 \\
\hline Propane & 0.23 & 0.17 & 0.21 & 0.19 \\
\hline Propene & 0.24 & 0.19 & 0.24 & 0.22 \\
\hline Iso-butane & 0.026 & 0.022 & 0.058 & 0.027 \\
\hline Chloromethane & 0.060 & 0.045 & 0.055 & 0.056 \\
\hline Butane & 0.067 & 0.055 & 0.066 & 0.059 \\
\hline 1-Butene & 0.056 & 0.043 & 0.067 & 0.052 \\
\hline 1,2-Propadiene & 0.010 & 0.0074 & 0.010 & 0.011 \\
\hline 1,3-Butadiene & 0.016 & 0.016 & 0.018 & 0.016 \\
\hline Isobutene & 0.054 & 0.043 & 0.055 & 0.044 \\
\hline cis-2-Butene & 0.039 & 0.033 & 0.043 & 0.038 \\
\hline Pentane & 0.019 & 0.014 & 0.018 & 0.017 \\
\hline Methanethiol & 0.013 & 0.0082 & 0.016 & 0.013 \\
\hline Hydrogen cyanide & 0.014 & 0.012 & 0.014 & 0.014 \\
\hline 1-Pentene & 0.015 & 0.013 & 0.017 & 0.0089 \\
\hline Furan & 0.020 & 0.012 & 0.015 & 0.017 \\
\hline Isoprene & 0.23 & 0.21 & 0.20 & 0.24 \\
\hline Hexane & 0.0070 & 0.0047 & 0.0061 & 0.0074 \\
\hline 1-Hexene & 0.013 & 0.010 & 0.014 & 0.013 \\
\hline Benzene & 0.14 & 0.085 & 0.13 & 0.087 \\
\hline Acetaldehyde & 0.61 & 0.44 & 0.74 & 0.36 \\
\hline Acrolein & 0.029 & 0.037 & 0.046 & 0.041 \\
\hline Propionaldehyde & 0.028 & 0.020 & 0.030 & 0.026 \\
\hline Acetonitrile & 0.040 & 0.0073 & 0.018 & 0.019 \\
\hline Toluene & 0.024 & 0.012 & 0.023 & 0.021 \\
\hline 2,5-Dimethylfuran & 0.010 & 0.0023 & 0.0086 & 0.010 \\
\hline Crotonaldehyde & 0.006 & 0.012 & 0.0090 & 0.0072 \\
\hline Isobutyraldehyde & 0.010 & 0.0075 & 0.0083 & 0.010 \\
\hline Sum & 46.9 & 34.2 & 53.0 & 46.9 \\
\hline
\end{tabular}


Table A3. Yield of different compounds analysed in TPM-F of the mainstream smoke of systems involving 1R5F tobacco. Yields are expressed in mg of compound/g of smoked tobacco (it is continued in the next page). nd = not detected compounds

\begin{tabular}{|c|c|c|c|c|}
\hline Compound & Family & 1R5F & $1 \mathrm{R} 5 \mathrm{~F}+\mathrm{C} 1$ & $1 \mathrm{R} 5 \mathrm{~F}+\mathrm{C} 2$ \\
\hline Pyridine, 4-methyl- & nitrogenous & 0.0060 & 0.0012 & 0.0033 \\
\hline Pyrazine, methyl- & nitrogenous & 0.0076 & 0.0033 & 0.0041 \\
\hline Furfural & carbonylic & 0.040 & 0.016 & 0.028 \\
\hline 2-Pentanone, 4-hydroxy-4-methyl- & carbonylic & 0.0097 & 0.0018 & 0.0045 \\
\hline Ethanol, 2-(1-methylethoxy)- & others & 0.0058 & 0.0015 & 0.0015 \\
\hline 2-Furanmethanol & epoxy & 0.0083 & 0.0004 & 0.0041 \\
\hline Pyridine, 3-methyl- & nitrogenous & 0.0050 & nd & 0.0027 \\
\hline 2-Propanone, 1-(acetyloxy)- & carbonylic & 0.014 & 0.0069 & 0.011 \\
\hline 4-Cyclopentene-1,3-dione & carbonylic & 0.017 & 0.0090 & 0.013 \\
\hline Styrene & aromatic & 0.0075 & 0.0020 & 0.0018 \\
\hline 2-Cyclopenten-1-one, 2-methyl- & carbonylic & 0.023 & 0.0071 & 0.015 \\
\hline 2-Acetylfuran & carbonylic & 0.016 & 0.0023 & 0.010 \\
\hline $2(5 \mathrm{H})$-furanone & carbonylic & 0.0097 & 0.0008 & 0.0084 \\
\hline Pyrazine, 2,3-dimethyl- & nitrogenous & 0.0010 & 0.0005 & 0.0006 \\
\hline 2-Hydroxycyclopent-2-en-1-one & carbonylic & 0.0065 & 0.0026 & 0.0051 \\
\hline Pyridine, 3,5-dimethyl- & nitrogenous & 0.0008 & nd & 0.0007 \\
\hline 2,5-Dimethyl-2-cyclopentenone & carbonylic & 0.0054 & 0.0021 & 0.0031 \\
\hline 2(3H)-furanone, 5-methyl- & carbonylic & 0.0013 & 0.0008 & 0.0013 \\
\hline Butanoic acid, 3-methyl- & others & 0.0040 & 0.0030 & 0.0018 \\
\hline Ethanol, 2-butoxy- & others & 0.0029 & 0.0012 & 0.0015 \\
\hline Benzaldehyde & carbonylic & 0.0067 & 0.0042 & 0.0055 \\
\hline Furfural, 5-methyl- & carbonylic & 0.017 & 0.0020 & 0.0037 \\
\hline Pyridine, 3-ethenyl- & nitrogenous & 0.0055 & 0.0004 & 0.0003 \\
\hline 2(5H)-Furanone, 3-methyl- & carbonylic & 0.0061 & 0.0019 & 0.0041 \\
\hline Phenol & phenolic & 0.054 & 0.018 & 0.040 \\
\hline 2-isopropylfuran & epoxy & 0.014 & nd & 0.0035 \\
\hline 2-Cyclopenten-1-one, 2-hydroxy-3-methyl- & carbonylic & 0.027 & 0.0034 & 0.017 \\
\hline Limonene & others & 0.031 & 0.0067 & 0.015 \\
\hline 2,3-Dimethyl-2-cyclopenten-1-one & carbonylic & 0.010 & 0.0029 & 0.0062 \\
\hline Indene & PAH & 0.010 & 0.0014 & 0.0074 \\
\hline o-Cresol & phenolic & 0.073 & 0.0088 & 0.020 \\
\hline nitrogenous & nitrogenous & 0.011 & 0.0044 & 0.0061 \\
\hline p-Cresol & phenolic & 0.0420 & 0.013 & 0.030 \\
\hline 2 ethyl tiophene & others & 0.0051 & 0.0023 & 0.0051 \\
\hline Phenol, 2-methoxy- & phenolic & 0.016 & 0.0060 & 0.012 \\
\hline 2-Propanamine & nitrogenous & 0.0056 & 0.0017 & 0.0057 \\
\hline 2,4-Dimethyl-4-cyclohexen-1,3-dione-one & carbonylic & 0.0059 & nd & 0.0052 \\
\hline 3-Ethyl-2-hydroxy-2-cyclopenten-1-one & carbonylic & 0.0095 & 0.0027 & 0.0070 \\
\hline 2,3-Dihydro-3,5-dihydroxy-6-methyl-4H-pyran-4-one & carbonylic & 0.014 & 0.0088 & 0.016 \\
\hline Phenol, 2,4-dimethyl- & phenolic & 0.011 & 0.0055 & 0.0085 \\
\hline Naphthalene & PAH & 0.0034 & 0.0019 & 0.0035 \\
\hline Ethanone, 1-(3-methylphenyl)- & carbonylic & 0.0053 & 0.0025 & 0.0042 \\
\hline p-cresol 2 methoxy & phenolic & 0.0032 & nd & 0.0016 \\
\hline 2,3-Dihydro-benzofuran & epoxy & 0.0072 & 0.0048 & 0.010 \\
\hline 1H-Inden-1-one, 2,3-dihydro- & carbonylic & 0.0071 & 0.0024 & 0.0067 \\
\hline Hydroquinone & phenolic & 0.021 & 0.0074 & 0.020 \\
\hline 1H-Indole & nitrogenous & 0.021 & 0.0078 & 0.016 \\
\hline 4-vinyl-2-methoxy-phenol & nitrogenous & 0.011 & 0.0022 & 0.0072 \\
\hline Nicotine & nitrogenous & 1.73 & 0.99 & 1.48 \\
\hline 1H-Indole, 3-methyl- & nitrogenous & 0.011 & 0.0045 & 0.012 \\
\hline Myosmine & nitrogenous & 0.022 & 0.012 & 0.019 \\
\hline Nicotyrine & nitrogenous & 0.026 & 0.017 & 0.022 \\
\hline Norsolanadiona & carbonylic & 0.011 & 0.0036 & 0.01 \\
\hline 2,3'-Bipyridine & nitrogenous & 0.033 & 0.026 & 0.033 \\
\hline Megastigmatrienone & carbonylic & 0.011 & 0.0096 & 0.010 \\
\hline Cotinine & nitrogenous & 0.016 & 0.0052 & 0.012 \\
\hline $\mathrm{N}(\mathrm{b})$-formylnornicotine & nitrogenous & 0.010 & nd & 0.0078 \\
\hline
\end{tabular}




\begin{tabular}{|c|c|c|c|c|}
\hline Compound & Family & 1R5F & $1 \mathrm{R5F}+\mathrm{C} 1$ & $1 \mathrm{R} 5 \mathrm{~F}+\mathrm{C} 2$ \\
\hline Neophytadiene & aliphatic & 0.16 & 0.099 & 0.12 \\
\hline 8-Quinolinemethanol & nitrogenous & 0.0044 & 0.0047 & 0.0064 \\
\hline Hexadecanoic acid, ethyl ester & others & 0.0062 & 0.0044 & 0.0073 \\
\hline Eicosane & aliphatic & 0.0041 & 0.0028 & 0.0043 \\
\hline pentadecane & aliphatic & 0.0026 & 0.0017 & 0.0032 \\
\hline Docosano & aliphatic & 0.0017 & 0.0015 & 0.0013 \\
\hline 2,6,10,14,18,22-Tetracosahexaene, $2,6,10,15,19,23$-hexamethyl- & aliphatic & 0.0036 & 0.0016 & 0.0031 \\
\hline Heptacosane & aliphatic & 0.012 & 0.0039 & 0.0095 \\
\hline Triacontane & aliphatic & 0.016 & 0.0045 & 0.012 \\
\hline Octadecane & aliphatic & 0.041 & 0.014 & 0.032 \\
\hline Tocopherol & phenolic & 0.0075 & 0.0020 & 0.0042 \\
\hline
\end{tabular}

Table A4. Yield of different compounds analysed in TPM-T of the mainstream smoke of systems involving $1 R 5 F$ tobacco. Yields are expressed in mg of compound/g of smoked tobacco (it is continued in the next page). nd = not detected compounds

\begin{tabular}{|c|c|c|c|c|}
\hline Compound & Family & 1R5F & $1 \mathrm{R} 5 \mathrm{~F}+\mathrm{C1}$ & $1 \mathrm{R} 5 \mathrm{~F}+\mathrm{C} 2$ \\
\hline 2-Pentanone, 4-hydroxy-4-methyl- & carbonylic & 0.0003 & nd & 0.0002 \\
\hline Ethanol, 2-(1-methylethoxy)- & others & 0.0007 & 0.0004 & 0.0006 \\
\hline 4-Cyclopentene-1,3-dione & carbonylic & 0.0002 & nd & 0.0002 \\
\hline Styrene & aromatic & 0.0003 & 0.0001 & 0.0002 \\
\hline Butanoic acid, 3-methyl- & others & 0.0002 & nd & 0.0000 \\
\hline Benzaldehyde & carbonylic & 0.0002 & 0.0001 & 0.0001 \\
\hline Limonene & others & 0.0005 & nd & 0.0000 \\
\hline p-Cresol & phenolic & 0.0009 & nd & 0.0006 \\
\hline 2 ethyl tiophene & others & 0.0004 & nd & 0.0000 \\
\hline 2,3-Dihydro-3,5-dihydroxy-6-methyl-4H-pyran-4-one & carbonylic & 0.0019 & 0.0003 & 0.0010 \\
\hline Phenol, 2,4-dimethyl- & phenolic & 0.0011 & nd & 0.0006 \\
\hline Phenol, 4-ethyl- & phenolic & 0.0010 & nd & 0.0000 \\
\hline 2,3-Dihydro-benzofuran & epoxy & 0.0019 & nd & 0.0008 \\
\hline 1H-Indole & nitrogenous & 0.0011 & nd & 0.0006 \\
\hline Nicotine & nitrogenous & 0.34 & 0.046 & 0.27 \\
\hline 1H-Indole, 3-methyl- & nitrogenous & 0.0011 & nd & 0.0008 \\
\hline Myosmine & nitrogenous & 0.0022 & nd & 0.0019 \\
\hline Nicotyrine & nitrogenous & 0.0040 & nd & 0.0022 \\
\hline 2,3'-Bipyridine & nitrogenous & 0.0018 & nd & 0.0014 \\
\hline Cotinine & nitrogenous & 0.0017 & nd & 0.0009 \\
\hline 5-Tetradecene & aliphatic & 0.0010 & nd & 0.0010 \\
\hline $\mathrm{N}(\mathrm{b})$-formylnornicotine & nitrogenous & 0.0025 & 0.0000 & 0.0037 \\
\hline Neophytadiene & aliphatic & 0.012 & 0.0030 & 0.011 \\
\hline Farnesol & others & 0.0010 & nd & 0.0009 \\
\hline Hexadecanoic acid, ethyl ester & others & 0.0007 & nd & 0.0005 \\
\hline Eicosane & aliphatic & 0.0006 & nd & 0.0003 \\
\hline Tricosane & aliphatic & 0.0012 & 0.0005 & 0.0010 \\
\hline 2,6,10,14,18,22-Tetracosahexaene, 2,6,10,15,19,23-hexamethyl- & aliphatic & 0.0013 & 0.0007 & 0.0011 \\
\hline Heptacosane & aliphatic & 0.0015 & 0.0006 & 0.0011 \\
\hline Tocopherol & phenolic & 0.0010 & nd & 0.0009 \\
\hline 2-Pentanone, 4-hydroxy-4-methyl- & carbonylic & 0.0003 & nd & 0.0002 \\
\hline Ethanol, 2-(1-methylethoxy)- & others & 0.0007 & 0.0004 & 0.0006 \\
\hline 4-Cyclopentene-1,3-dione & carbonylic & 0.0002 & nd & 0.0002 \\
\hline Styrene & aromatic & 0.0003 & 0.0001 & 0.0002 \\
\hline Butanoic acid, 3-methyl- & others & 0.0002 & nd & 0.0000 \\
\hline Benzaldehyde & carbonylic & 0.0002 & 0.0001 & 0.0001 \\
\hline Limonene & others & 0.0005 & nd & 0.0000 \\
\hline o-Cresol & phenolic & 0.0006 & nd & 0.0004 \\
\hline p-Cresol & phenolic & 0.0009 & nd & 0.0006 \\
\hline 2 ethyl tiophene & others & 0.0004 & nd & 0.0000 \\
\hline 2,3-Dihydro-3,5-dihydroxy-6-methyl-4H-pyran-4-one & carbonylic & 0.0019 & 0.0003 & 0.0010 \\
\hline Phenol, 2,4-dimethyl- & phenolic & 0.0011 & nd & 0.0006 \\
\hline
\end{tabular}




\begin{tabular}{|c|c|c|c|c|}
\hline Compound & Family & 1R5F & $1 \mathrm{R} 5 \mathrm{~F}+\mathrm{C1}$ & $1 \mathrm{R} 5 \mathrm{~F}+\mathrm{C2}$ \\
\hline Phenol, 4-ethyl- & phenolic & 0.0010 & nd & 0.0000 \\
\hline 2,3-Dihydro-benzofuran & epoxy & 0.0019 & nd & 0.0008 \\
\hline 1H-Indole & nitrogenous & 0.0011 & nd & 0.0006 \\
\hline 4-vinyl-2-methoxy-phenol & phenolic & 0.0004 & nd & 0.0000 \\
\hline Nicotine & nitrogenous & 0.34 & 0.046 & 0.27 \\
\hline 1H-Indole, 3-methyl- & nitrogenous & 0.0011 & nd & 0.0008 \\
\hline Myosmine & nitrogenous & 0.0022 & nd & 0.0019 \\
\hline Nicotyrine & nitrogenous & 0.0040 & nd & 0.0022 \\
\hline 2,3'-Bipyridine & nitrogenous & 0.0018 & nd & 0.0014 \\
\hline Cotinine & nitrogenous & 0.0017 & nd & 0.0009 \\
\hline 5-Tetradecene & aliphatic & 0.0010 & nd & 0.0010 \\
\hline $\mathrm{N}(\mathrm{b})$-formylnornicotine & nitrogenous & 0.0025 & 0.0000 & 0.0037 \\
\hline Neophytadiene & aliphatic & 0.012 & 0.0030 & 0.011 \\
\hline Farnesol & others & 0.0010 & nd & 0.0009 \\
\hline Hexadecanoic acid, ethyl ester & others & 0.0007 & nd & 0.0005 \\
\hline Eicosane & aliphatic & 0.0006 & nd & 0.0003 \\
\hline Tricosane & aliphatic & 0.0012 & 0.0005 & 0.0010 \\
\hline 2,6,10,14,18,22-Tetracosahexaene, 2,6,10,15,19,23-hexamethyl- & aliphatic & 0.0013 & 0.0007 & 0.0011 \\
\hline Heptacosane & aliphatic & 0.0015 & 0.0006 & 0.0011 \\
\hline Triacontane & aliphatic & 0.0017 & 0.0007 & 0.0010 \\
\hline Octadecane & aliphatic & 0.0036 & 0.0012 & 0.0031 \\
\hline Tocopherol & phenolic & 0.0010 & nd & 0.0009 \\
\hline
\end{tabular}

Table A5. Yield of different compounds analysed in the TPM-F of the mainstream smoke of systems involving 3R4F tobacco. Yields expressed in terms of mg of compound/g of smoked tobacco (it is continued in the next pages). $n d=$ not detected compounds

\begin{tabular}{|c|c|c|c|c|c|}
\hline Compound & Family & 3R4F & $3 \mathrm{R} 4 \mathrm{~F}+\mathrm{C} 1$ & $3 \mathrm{R} 4 \mathrm{~F}+\mathrm{C} 2$ & $3 \mathrm{R} 4 \mathrm{~F}+\mathrm{C} 3$ \\
\hline Pyridine, 4-methyl- & nitrogenous & 0.0081 & 0.0031 & 0.0054 & 0.0099 \\
\hline Pyrazine, methyl- & nitrogenous & 0.0056 & 0.0027 & 0.0044 & 0.0052 \\
\hline Furfural & carbonylic & 0.0508 & 0.0218 & 0.0387 & 0.0750 \\
\hline 2-Pentanone, 4-hydroxy-4-methyl- & carbonylic & 0.0023 & nd & nd & 0.0013 \\
\hline Ethanol, 2-(1-methylethoxy)- & others & 0.0039 & 0.0010 & 0.0040 & 0.0079 \\
\hline 2-Furanmethanol & epoxy & 0.0096 & 0.0015 & 0.0057 & 0.0000 \\
\hline Pyridine, 3-methyl- & nitrogenous & 0.0145 & 0.0011 & 0.0069 & 0.0169 \\
\hline 2-Propanone, 1-(acetyloxy)- & carbonylic & 0.0182 & 0.0065 & 0.0103 & 0.0188 \\
\hline 4-Cyclopentene-1,3-dione & carbonylic & 0.0145 & 0.0058 & 0.0102 & 0.0169 \\
\hline Styrene & aromatic & 0.0028 & 0.0019 & 0.0036 & 0.0039 \\
\hline 2-Cyclopenten-1-one, 2-methyl- & carbonylic & 0.0218 & 0.0086 & 0.0169 & 0.0254 \\
\hline 2-Acetylfuran & carbonylic & 0.0133 & 0.0052 & 0.0104 & 0.0169 \\
\hline $2(5 \mathrm{H})$-furanone & carbonylic & 0.0097 & 0.0002 & 0.0011 & 0.0116 \\
\hline Pyrazine, 2,3-dimethyl- & nitrogenous & 0.0018 & 0.0001 & 0.0013 & nd \\
\hline 2-Hydroxycyclopent-2-en-1-one & carbonylic & 0.0087 & 0.0018 & 0.0042 & 0.0022 \\
\hline Pyridine, 3,5-dimethyl- & nitrogenous & 0.0040 & 0.0004 & nd & 0.0038 \\
\hline 2,5-Dimethyl-2-cyclopentenone & carbonylic & 0.0040 & 0.0025 & 0.0041 & 0.0045 \\
\hline 2(3H)-furanone, 5-methyl- & carbonylic & 0.0022 & 0.0006 & 0.0010 & 0.0025 \\
\hline Butanoic acid, 3-methyl- & others & 0.0025 & 0.0008 & 0.0022 & nd \\
\hline Ethanol, 2-butoxy- & others & 0.0021 & 0.0012 & 0.0025 & 0.0046 \\
\hline Benzaldehyde & carbonylic & 0.0084 & 0.0035 & 0.0034 & 0.0146 \\
\hline Furfural, 5-methyl- & carbonylic & 0.0266 & 0.0028 & 0.0169 & 0.0303 \\
\hline Pyridine, 3-ethenyl- & nitrogenous & 0.0050 & 0.0053 & 0.0115 & 0.0053 \\
\hline 2(5H)-Furanone, 3-methyl- & carbonylic & 0.0064 & 0.0019 & 0.0041 & 0.0097 \\
\hline Phenol & phenolic & 0.0508 & 0.0169 & 0.0387 & 0.0690 \\
\hline 2-isopropylfuran & epoxy & 0.0067 & nd & nd & nd \\
\hline 2-Cyclopenten-1-one, 2-hydroxy-3-methyl- & carbonylic & 0.0230 & 0.0082 & 0.0145 & 0.0363 \\
\hline Limonene & others & 0.0133 & 0.0206 & 0.0206 & 0.0399 \\
\hline Benzenemethanol & aromatic & 0.0022 & 0.0028 & 0.0034 & nd \\
\hline 2,3-Dimethyl-2-cyclopenten-1-one & carbonylic & 0.0133 & 0.0042 & 0.0092 & 0.0120 \\
\hline Indene & PAH & 0.0056 & 0.0019 & 0.0069 & 0.0076 \\
\hline o-Cresol & phenolic & 0.0266 & 0.0087 & 0.0303 & 0.0399 \\
\hline 2-Acetylpyrrole & nitrogenous & 0.0030 & 0.0021 & 0.0034 & 0.0019 \\
\hline Phenol, 4-methoxy- & phenolic & 0.0038 & 0.0010 & 0.0034 & 0.0050 \\
\hline Ethanone, 1-phenyl- & carbonylic & 0.0029 & 0.0010 & 0.0018 & 0.0045 \\
\hline p-Cresol & phenolic & 0.0351 & 0.0133 & 0.0327 & 0.0508 \\
\hline 2 ethyl tiophene & others & 0.0018 & 0.0029 & 0.0035 & 0.0000 \\
\hline Phenol, 2-methoxy- & phenolic & 0.0206 & 0.0077 & 0.0157 & 0.0218 \\
\hline 2-Propanamine & nitrogenous & 0.0070 & 0.0016 & 0.0044 & 0.0351 \\
\hline
\end{tabular}




\begin{tabular}{|c|c|c|c|c|c|}
\hline Compound & Family & 3R4F & $3 \mathrm{R} 4 \mathrm{~F}+\mathrm{C1}$ & $3 R 4 F+C 2$ & $3 \mathrm{R} 4 \mathrm{~F}+\mathrm{C3}$ \\
\hline 2,4-Dimethyl-4-cyclohexen-1,3-dione-one & carbonylic & nd & nd & nd & nd \\
\hline 3-Ethyl-2-hydroxy-2-cyclopenten-1-one & carbonylic & 0.0121 & 0.0034 & 0.0085 & 0.0157 \\
\hline Benzeneacetonitrile & nitrogenous & 0.0068 & 0.0025 & 0.0050 & 0.0068 \\
\hline 2,3-Dihydro-3,5-dihydroxy-6-methyl-4H-pyran-4-one & carbonylic & 0.0038 & 0.0067 & 0.0034 & 0.0157 \\
\hline Phenol, 2,4-dimethyl- & phenolic & 0.0074 & 0.0061 & 0.0042 & 0.0145 \\
\hline Phenol, 4-ethyl- & phenolic & 0.0090 & 0.0028 & 0.0034 & 0.0133 \\
\hline Naphthalene & PAH & 0.0051 & 0.0022 & 0.0050 & 0.0054 \\
\hline Ethanone, 1-(3-methylphenyl)- & carbonylic & 0.0030 & 0.0024 & 0.0035 & 0.0021 \\
\hline p-cresol 2 methoxy & phenolic & 0.0030 & 0.0008 & 0.0035 & 0.0036 \\
\hline 2,3-Dihydro-benzofuran & epoxy & 0.0067 & 0.0041 & 0.0090 & 0.0077 \\
\hline 2-furancarboxaldehyde, 5-(hydroxymethyl)- & carbonylic & 0.0070 & 0.0011 & 0.0053 & nd \\
\hline 1H-Inden-1-one, 2,3-dihydro- & carbonylic & 0.0104 & 0.0027 & 0.0069 & 0.0121 \\
\hline Hydroquinone & phenolic & 0.0291 & 0.0054 & 0.0054 & 0.0218 \\
\hline 1H-Indole & nitrogenous & 0.0169 & 0.0157 & 0.0266 & 0.0145 \\
\hline 4-vinyl-2-methoxy-phenol & phenolic & 0.0105 & 0.0053 & 0.0076 & 0.0097 \\
\hline Nicotine & nitrogenous & 1.2093 & 0.6428 & 1.0858 & 1.2299 \\
\hline 1H-Indole, 3-methyl- & nitrogenous & 0.0119 & 0.0041 & 0.0074 & 0.0133 \\
\hline Myosmine & nitrogenous & 0.0145 & 0.0052 & 0.0116 & 0.0116 \\
\hline Phenol, 2-methoxy-4-(2-propenyl)- & phenolic & 0.0114 & 0.0016 & 0.0080 & 0.0116 \\
\hline Nicotyrine & nitrogenous & 0.0117 & 0.0069 & 0.0145 & 0.0117 \\
\hline Norsolanadiona & carbonylic & 0.0047 & 0.0025 & 0.0051 & 0.0042 \\
\hline 2,3'-Bipyridine & nitrogenous & 0.0169 & 0.0075 & 0.0145 & 0.0242 \\
\hline 1,4-dihydrophenantrhene & PAH & 0.0075 & nd & nd & 0.0087 \\
\hline Diethyl phatalate & carbonylic & 0.0069 & 0.0042 & 0.0084 & 0.0075 \\
\hline Megastigmatrienone & carbonylic & 0.0063 & 0.0039 & 0.0062 & 0.0145 \\
\hline N-propyl- nornicotine & nitrogenous & 0.0045 & nd & nd & 0.0046 \\
\hline Cotinine & nitrogenous & 0.0145 & 0.0077 & 0.0113 & 0.0121 \\
\hline 1H-Indene, 2,3-dihydro-1,1,3-trimethyl-3-phenyl- & aromatic & 0.0036 & 0.0023 & 0.0034 & 0.0075 \\
\hline 5-Tetradecene & aliphatic & 0.0092 & nd & nd & 0.0122 \\
\hline $\mathrm{N}$ (b)-formylnornicotine & nitrogenous & 0.0022 & 0.0019 & 0.0039 & 0.0019 \\
\hline 2,4-Diphenyl-4-methyl-penten-1 ene & aromatic & 0.0038 & 0.0011 & 0.0017 & nd \\
\hline Neophytadiene & aliphatic & 0.1017 & 0.0714 & 0.0980 & 0.1404 \\
\hline Farnesol & others & 0.0062 & 0.0041 & 0.0059 & 0.0073 \\
\hline 8-Quinolinemethanol & nitrogenous & 0.0133 & nd & 0.0079 & 0.0063 \\
\hline DBP & carbonylic & nd & nd & nd & nd \\
\hline Hexadecanoic acid, ethyl ester & others & 0.0090 & 0.0027 & 0.0097 & 0.0157 \\
\hline Eicosane & aliphatic & 0.0028 & 0.0017 & 0.0033 & 0.0016 \\
\hline pentadecane & aliphatic & 0.0013 & 0.0008 & 0.0013 & nd \\
\hline Docosane & aliphatic & 0.0012 & nd & nd & nd \\
\hline Tricosane & aliphatic & 0.0133 & 0.0047 & 0.0061 & nd \\
\hline 2,6,10,14,18,22-Tetracosahexaene, $2,6,10,15,19,23$-hexamethyl- & aliphatic & 0.0056 & 0.0018 & 0.0033 & 0.0053 \\
\hline Heptacosane & aliphatic & 0.0169 & 0.0044 & 0.0074 & 0.0133 \\
\hline Triacontane & aliphatic & 0.0206 & 0.0030 & 0.0050 & 0.0182 \\
\hline Octadecane & aliphatic & 0.0460 & 0.0113 & 0.0242 & 0.0424 \\
\hline Tocopherol & phenolic & 0.0206 & 0.0033 & 0.0070 & 0.0157 \\
\hline
\end{tabular}

Table A6. Yield of different compounds analysed in the TPM-T of the mainstream smoke of systems involving 3R4F tobacco. Yields are expressed in mg of compound/g of smoked tobacco (it is continued in the next page). $n d=$ not detected compounds

\begin{tabular}{|c|c|c|c|c|c|}
\hline Compound & Family & 3R4F & $3 \mathrm{R} 4 \mathrm{~F}+\mathrm{C1}$ & $3 \mathrm{R} 4 \mathrm{~F}+\mathrm{C} 2$ & $3 \mathrm{R} 4 \mathrm{~F}+\mathrm{C3}$ \\
\hline Pyridine, 4-methyl- & nitrogenous & 0.0004 & nd & nd & nd \\
\hline Pyrazine, methyl- & nitrogenous & 0.0006 & nd & nd & nd \\
\hline Furfural & carbonylic & 0.0008 & nd & 0.0001 & nd \\
\hline 2-Pentanone, 4-hydroxy-4-methyl- & carbonylic & 0.0007 & nd & 0.0004 & 0.0006 \\
\hline Ethanol, 2-(1-methylethoxy)- & others & 0.0016 & 0.0004 & 0.0008 & 0.0016 \\
\hline Pyridine, 3-methyl- & nitrogenous & 0.0002 & nd & nd & nd \\
\hline 2-Propanone, 1-(acetyloxy)- & carbonylic & 0.0002 & nd & nd & nd \\
\hline Styrene & aromatic & 0.0001 & 0.0001 & 0.0001 & nd \\
\hline 2-Cyclopenten-1-one, 2-methyl- & carbonylic & 0.0013 & nd & nd & 0.0005 \\
\hline 2-Acetylfuran & carbonylic & 0.0004 & nd & nd & nd \\
\hline $2(5 \mathrm{H})$-furanone & carbonylic & 0.0001 & nd & nd & nd \\
\hline 2-Hydroxycyclopent-2-en-1-one & carbonylic & 0.0010 & nd & nd & nd \\
\hline Pyridine, 3,5-dimethyl- & nitrogenous & 0.0002 & nd & nd & nd \\
\hline 2,5-Dimethyl-2-cyclopentenone & carbonylic & 0.0007 & nd & nd & 0.0002 \\
\hline Butanoic acid, 3-methyl- & others & 0.0022 & nd & 0.0006 & nd \\
\hline
\end{tabular}




\begin{tabular}{|c|c|c|c|c|c|}
\hline Compound & Family & 3R4F & $3 \mathrm{R} 4 \mathrm{~F}+\mathrm{Cl}$ & $3 \mathrm{R} 4 \mathrm{~F}+\mathrm{C2}$ & $3 \mathrm{R} 4 \mathrm{~F}+\mathrm{C} 3$ \\
\hline Benzaldehyde & carbonylic & 0.0004 & nd & 0.0001 & nd \\
\hline Furfural, 5-methyl- & carbonylic & 0.0002 & nd & nd & nd \\
\hline Phenol & phenolic & 0.0050 & nd & 0.0005 & 0.0064 \\
\hline 2-isopropylfuran & epoxy & 0.0004 & nd & nd & nd \\
\hline 2-Cyclopenten-1-one, 2-hydroxy-3-methyl- & carbonylic & 0.0029 & nd & nd & nd \\
\hline Limonene & others & 0.0028 & nd & nd & 0.0023 \\
\hline 2,3-Dimethyl-2-cyclopenten-1-one & carbonylic & 0.0004 & nd & nd & nd \\
\hline o-Cresol & phenolic & 0.0044 & 0.0002 & 0.0008 & 0.0035 \\
\hline p-Cresol & phenolic & 0.0070 & 0.0002 & 0.0017 & 0.0052 \\
\hline 2 ethyl tiophene & others & 0.0012 & 0.0004 & 0.0010 & 0.0008 \\
\hline Phenol, 2-methoxy- & phenolic & 0.0022 & nd & 0.0002 & 0.0010 \\
\hline 2-Propanamine & nitrogenous & 0.0029 & nd & 0.0005 & 0.0019 \\
\hline 3-Ethyl-2-hydroxy-2-cyclopenten-1-one & carbonylic & 0.0048 & nd & nd & 0.0024 \\
\hline 2,3-Dihydro-3,5-dihydroxy-6-methyl-4H-pyran-4-one & carbonylic & 0.0084 & 0.0013 & 0.0057 & 0.0052 \\
\hline Phenol, 2,4-dimethyl- & phenolic & 0.0036 & 0.0005 & 0.0015 & 0.0041 \\
\hline Phenol, 4-ethyl- & phenolic & 0.0033 & 0.0006 & 0.0008 & 0.0030 \\
\hline Naphthalene & PAH & 0.0090 & nd & nd & nd \\
\hline p-cresol 2 methoxy & phenolic & 0.0021 & nd & 0.0005 & nd \\
\hline 2,3-Dihydro-benzofuran & epoxy & 0.0035 & 0.0011 & 0.0015 & 0.0034 \\
\hline 2-furancarboxaldehyde, 5-(hydroxymethyl)- & carbonylic & 0.0028 & 0.0000 & 0.0010 & nd \\
\hline 1H-Inden-1-one, 2,3-dihydro- & carbonylic & 0.0018 & nd & nd & 0.0025 \\
\hline Hydroquinone & phenolic & 0.0169 & nd & 0.0047 & 0.0090 \\
\hline 1H-Indole & nitrogenous & 0.0099 & 0.0008 & 0.0027 & 0.0030 \\
\hline 4-vinyl-2-methoxy-phenol & phenolic & 0.0058 & 0.0004 & 0.0015 & 0.0045 \\
\hline Nicotine & nitrogenous & 0.9587 & 0.2203 & 0.6367 & 0.7481 \\
\hline 1H-Indole, 3-methyl- & nitrogenous & 0.0045 & 0.0006 & 0.0017 & 0.0047 \\
\hline Myosmine & nitrogenous & 0.0075 & 0.0008 & 0.0030 & 0.0067 \\
\hline Phenol, 2-methoxy-4-(2-propenyl)- & phenolic & 0.0041 & nd & 0.0016 & 0.0024 \\
\hline Nicotyrine & nitrogenous & 0.0051 & 0.0021 & 0.0038 & 0.0052 \\
\hline Norsolanadiona & carbonylic & 0.0038 & nd & 0.0016 & 0.0027 \\
\hline 2,3'-Bipyridine & nitrogenous & 0.0073 & 0.0012 & 0.0042 & 0.0065 \\
\hline 1,4-dihydrophenantrhene & $\mathrm{PAH}$ & 0.0070 & nd & 0.0008 & nd \\
\hline Diethyl phatalate & carbonylic & 0.0085 & 0.0011 & 0.0011 & 0.0036 \\
\hline Megastigmatrienone & carbonylic & 0.0039 & 0.0007 & 0.0023 & 0.0036 \\
\hline $\mathrm{N}$-propyl- nornicotine & nitrogenous & 0.0035 & nd & 0.0008 & 0.0019 \\
\hline Cotinine & nitrogenous & 0.0111 & 0.0010 & 0.0069 & 0.0109 \\
\hline 5-Tetradecene & aliphatic & 0.0035 & nd & 0.0019 & nd \\
\hline $\mathrm{N}(\mathrm{b})$-formylnornicotine & nitrogenous & 0.0103 & 0.0017 & 0.0046 & 0.0047 \\
\hline NEOPHYTADIENE & aliphatic & 0.0602 & 0.0110 & 0.0369 & 0.0606 \\
\hline Farnesol & others & 0.0047 & 0.0012 & 0.0030 & 0.0040 \\
\hline 8-Quinolinemethanol & nitrogenous & 0.0056 & nd & nd & 0.0012 \\
\hline DBP & carbonylic & 0.0021 & nd & nd & 0.0012 \\
\hline Hexadecanoic acid, ethyl ester & others & 0.0059 & 0.0004 & 0.0034 & 0.0073 \\
\hline Eicosane & aliphatic & 0.0013 & 0.0002 & 0.0010 & 0.0012 \\
\hline pentadecane & aliphatic & 0.0015 & nd & 0.0007 & nd \\
\hline Docosano & aliphatic & 0.0021 & nd & 0.0000 & nd \\
\hline Tricosane & aliphatic & 0.0082 & 0.0008 & 0.0027 & nd \\
\hline $2,6,10,14,18,22$-Tetracosahexaene, $2,6,10,15,19,23$-hexamethyl- & aliphatic & 0.0050 & 0.0006 & 0.0013 & 0.0025 \\
\hline Heptacosane & aliphatic & 0.0157 & 0.0011 & 0.0036 & 0.0076 \\
\hline Triacontane & aliphatic & 0.0145 & 0.0012 & 0.0025 & 0.0133 \\
\hline Octadecane & aliphatic & 0.0339 & 0.0033 & 0.0076 & 0.0182 \\
\hline Tocopherol & phenolic & 0.0182 & 0.0013 & 0.0023 & 0.0111 \\
\hline Pyridine, 4-methyl- & nitrogenous & 0.0004 & nd & nd & nd \\
\hline Pyrazine, methyl- & nitrogenous & 0.0006 & nd & nd & nd \\
\hline Furfural & carbonylic & 0.0008 & nd & 0.0001 & nd \\
\hline 2-Pentanone, 4-hydroxy-4-methyl- & carbonylic & 0.0007 & nd & 0.0004 & 0.0006 \\
\hline Ethanol, 2-(1-methylethoxy)- & others & 0.0016 & 0.0004 & 0.0008 & 0.0016 \\
\hline Pyridine, 3-methyl- & nitrogenous & 0.0002 & nd & nd & nd \\
\hline 2-Propanone, 1-(acetyloxy)- & carbonylic & 0.0002 & nd & nd & nd \\
\hline 4-Cyclopentene-1,3-dione & carbonylic & 0.0004 & 0.0001 & 0.0001 & nd \\
\hline Styrene & aromatic & 0.0001 & 0.0001 & 0.0001 & nd \\
\hline 2-Cyclopenten-1-one, 2-methyl- & carbonylic & 0.0013 & nd & nd & 0.0005 \\
\hline 2-Acetylfuran & carbonylic & 0.0004 & nd & nd & nd \\
\hline $2(5 \mathrm{H})$-furanone & carbonylic & 0.0001 & nd & nd & nd \\
\hline 2-Hydroxycyclopent-2-en-1-one & carbonylic & 0.0010 & nd & nd & nd \\
\hline Pyridine, 3,5-dimethyl- & nitrogenous & 0.0002 & nd & nd & nd \\
\hline 2,5-Dimethyl-2-cyclopentenone & carbonylic & 0.0007 & nd & nd & 0.0002 \\
\hline
\end{tabular}




\section{References}

[1] M. Borgerding, H. Klus, "Analysis of complex mixtures-cigarette smoke", Exp. Toxicol. Pathol., vol. 57, pp. 43-73, 2005.

[2] M.E. Counts, M.J. Morton, S.W. Laffoon, R.H. Cox, R.H., P.J. Lipowicz, "Development of a commercial cigarette "market map" comparison methodology for evaluating new or non-conventional cigarettes", Regul. Toxicol. Pharm, vol. 41, pp. 185-227., 2005.

[3] D. Hammond, G.T. Fong, K.M. Cummings, R.J. O'Connor, G.A Giovino, A. McNeill, "C0igarette Yields and Human Exposure, A Comparison of Alternative Testing Regimens", Cancer Epidem. Biomar., vol. 15, pp. 1495-1501, 2006.

[4] A. Marcilla, A. Gómez-Siurana, D. Berenguer, I. Martínez-Castellanos, M.I. Beltrán, "Comparative study of the main characteristics and composition of the mainstream smoke of ten cigarette brands sold in Spain", Food Chem. Toxicol., vol. 50, pp. 1317-1333, 2012.

[5] R.R. Baker, L.J. Bishop, L.J., "The pyrolysis of non-volatile tobacco ingredients using a system that simulates cigarette combustion conditions", J. Anal. Appl. Pyrol., vol. 74, pp. 145-170, 2005.

[6] R.R. Baker, "Smoke generation inside a burning cigarette, modifying combustion to develop cigarette that may be less hazardous to health", Prog. Energ. Combust., vol. 32, pp. $373-385,2006$.

[7] M.F. Borgerding, J.A. Bodnar, H.L. Chung, P.P. Mangan, C.C. Morrison, J.C. Risner, C.H. Rogers, D.F. Simmons, M.S. Uhrig, F.N. Wendelboe, D.E. Wingate, L.S. Winkler, "Chemical and biological studies of a new cigarette that primarily heats tobacco. Part 1. Chemical composition of mainstream smoke", Food Chem. Toxicol., vol. 36, pp. 169-182, 1998.

[8] J. Fowles, E. Dybing, "Application of toxicological risk assessment principles to the chemical constituents of cigarette smoke" Tob. Control, vol. 124, pp. 424-430, 2003.

[9] D. Hoffmann, I. Hoffmann, "The changing cigarette; 1950-1995", J. Toxicol. Environ. Health, vol. 50, pp. 307-364, 1997.

[10] E. Roemer, R.A. Carchman, "Limitations of cigarette machine smoking regimens", Toxicol. Lett., vol. 2031, pp. 20-27, 2011.

[11] E. Roemer, H. Schramke, H. Weiler, A. Buettner, S. Kausche, S Weber, A. Berges, M. Stueber, M. Muench, E. Trelles-Sticken, J. Pype, K. Kohlgrueber, H. Voelkel, S. Wittke, "Mainstream smoke chemistry and in vitro and in vivo toxicity of the reference cigarettes 3R4F and 2R4F" Beitr. Tabakforsch., vol. 251, pp. 316-335, 2012.

[12] W.M. Meier, K. Siegmann, "Significant reduction of carcinogenic compounds in tobacco smoke by the use of zeolite catalysts" Micropor. Mesopor. Mat., vol. 33, 307-310, 1999.

[13] G. Yong, Z. Jin, H. Tong, X. Yan, G. Li, S. Liu, "Selective reduction of bulky polycyclic aromatic hydrocarbons from mainstream smoke of cigarettes by mesoporous materials", Micropor. Mesopor. Mat., vol. 91, pp. 238-243, 2006.
[14] Z. Chen, L. Zhang, Y. Tang, Z. Jia, "Adsorption of nicotine and tar from the mainstream smoke of cigarettes by oxidized carbon nanotubes", Appl. Surf. Sci., vol. 252, pp. 2933-2937, 2006.

[15] Y. Xu, J.H. Zhu, L.L. Ma, A. Ji, J.L. Wei, X.Y. Shang, "Removing nitrosamines from mainstream smoke of cigarettes by zeolites" Micropor. Mesopor. Mat., vol. 60, pp. 125-138, 2003.

[16] P. Li, M. Hajaligol, "Oxidant/catalyst nanoparticles to reduce carbon monoxide in the mainstream smoke of a cigarette" US Patent Application 20030075193; Kind Code A1, 2003.

[17] R. Vesna, A. Sladjana, A. Borivoj, M.M. Abduladhim, "Effect of varied quantities of zeolite on the reduction of polycyclic aromatic hydrocarbons in tobacco smoke", Afri. J. Biotechnol., vol. 1142, pp. 10041-10047, 2012.

[18] W.G. Lin, Y. Zhou, F.N. Zhou, S.L. Zhou, J.H. Zhu, "Catalytic degradation of tobacco-specific nitrosamines by ferric zeolite", Appl. Catal. B-Environ., vol. 129, pp. 301-308, 2013.

[19] Q. Deng, C. Huang, W. Xie, J. Zhang, Y. Zhao, Z. Hong, A. Pang, M. Wei, "Significant reduction of harmful compounds in tobacco smoke by the use of titanate nanosheets and nanotubes", Chem. Commun., vol. 47, pp. 6153-6155, 2011.

[20] W.G. Lin, Y. Zhou, Y. Cao, S.L. Zhou, M.M. Wan, Y. Wang, J.H Zhu, "Applying heterogeneous catalysis to health care, In situ elimination of tobacco-specific nitrosamines TSNAs in smoke by molecular sieves" Catal. Today., vol. 212, pp. 52-61, 2013.

[21] A. Marcilla, A. Gómez-Siurana, D. Berenguer, I. Martínez-Castellanos, M.I. Beltrán, "Reduction of tobacco smoke components yields by zeolites and synthesized Al-MCM-41", Micropor. Mesopor. Mat., vol. 161, pp. 14-24, 2012.

[22] A. Marcilla, M.I. Beltrán, A. Gómez-Siurana, I. Martínez, D. Berenguer, "Template removal in MCM-41 type materials by solvent extraction, Influence of the treatment on the textural properties of the material and the effect on its behaviour as catalyst for reducing tobacco smoking toxicity", Chem. Eng. Res. Des., vol. 8911, pp. 2330-2343, 2011.

[23] A. Marcilla, A. Gómez-Siurana, M. Beltrán, I. Martínez, D. Berenguer, "Evaluation of the efficiency of solvent extraction for template removal in the synthesis of MCM-41 type materials to be used as tobacco additives for smoke toxicity reduction", Applied Catalysis A-General, vol. 378, pp. 107-113, 2010.

[24] A. Marcilla, I. Beltrán, A. Gómez, R. Navarro, D. Berenguer, I. Martínez, "Tobacco-catalyst mixtures for reducing the toxic compounds present in tobacco smoke", EURO-PCT078230349 2009.

[25] A.F. Marcilla Gomis, A. Gómez Siurana, M.I. Beltrán Rico, I. Martínez Castellanos, D. Berenguer Muñoz, "Aluminosilicato sab-15 como aditivo para la reducción de los compuestos tóxicos y cancerígenos presentes en el humo del tabaco", Spain Patent P201201266 2009.

[26] F. Zhang, Y. Yan, H. Yang, Y. Meng, C. Yu, B. Tu, D. Zhao, "Understanding Effect of Wall Structure on the Hydrothermal Stability of Mesostructured Silica SBA-15", J. Phys. Chem. B, vol. 109, pp. 8723-8732, 2005.

[27] T.R. Gaydhankar, V. Samuel, R.K. Jha, R. Kumar, P.N. Josh, "Room temperature synthesis of Si-MCM-41 using polymeric version of ethyl silicate as a source of silica", Materials Research Bulletin, vol. 42, pp. 1473-1484, 2007. 

1R5F Reference Cigarettes

[28] L.Y. Chen, Z. Ping, G.K. Chuah, S. Jaenicke, G.A. Simon, "comparison of post-synthesis alumination and sol-gel synthesis of MCM-41 with high framework aluminium content", Micropor. Mesopor. Mat., vol. 27, pp. 231-242, 1999.
[29] J. Aguado, D.P. Serrano, J.M. Escola, "A sol-gel approach for the room temperature synthesis of Al-containing micelle-templated silica", Micropor. Mesopor. Mat., vol. 34, pp. 43-54, 2000. 